\title{
Early Intervention for Obsessive Compulsive Disorder: An Expert Consensus Statement
}

Naomi A Fineberg ${ }^{1,2,3}$, Bernardo Dell'Osso ${ }^{4,5,6,7}$, Umberto Albert ${ }^{23}$, Giuseppe Maina ${ }^{21,24}$, Daniel Geller ${ }^{28}$, Lior Carmi ${ }^{8}$, Nick Sireau, Susanne Walitza ${ }^{26}$, Giacomo Grassi ${ }^{10,19}$, Stefano Pallanti ${ }^{9,19}$, Eric Hollander ${ }^{11}$, Vlasios Brakoulias ${ }^{25}$, Jose M Menchon ${ }^{12}$, Donatella Marazziti ${ }^{20}$, Konstantinos loannidis ${ }^{13,14}$, Annemieke Apergis-Schoute ${ }^{29}$, Dan J Stein ${ }^{15}$, Danielle C Cath ${ }^{27}$, Dick J Veltman ${ }^{30}$, Michael Van Ameringen ${ }^{16}$, Leonardo F Fontenelle ${ }^{22}$, Roseli G Shavitt ${ }^{18}$, Daniel Costa ${ }^{18}$, Juliana B Diniz ${ }^{18}$ and Joseph Zohar ${ }^{17}$.

1. Hertfordshire Partnership University NHS Foundation Trust, Rosanne House, Welwyn Garden City, Hertfordshire AL8 6HG, UK

2. Center for Clinical \& Health Research Services, School of Life and Medical Sciences, University of Hertfordshire, Hatfield, UK

3. School of Clinical Medicine, University of Cambridge, Cambridge, UK

4. Department of Biomedical and Clinical Sciences "Luigi Sacco", University of Milan, Milan, Italy

5. Department of Psychiatry, ASST Fatebenefratelli-Sacco, Via GB Grassi 74, 20157, Milan, Italy

6. Department of Psychiatry and Behavioral Sciences, Stanford University, Stanford, CA, USA

7. Fondazione IRCCS Ca' Granda and CRC "Aldo Ravelli" for Neurotechnology and Experimental Brain Therapeutics, University of Milan, Italy

8. School of Psychological Sciences, Tel Aviv University, Tel Aviv, Israel

9. Department of Psychiatry, Stanford University, California, USA

10. Department of Neuroscience, Psychology, Drug Research and Child Health - Neurofarba, University of Florence, Italy

11. Department of Psychiatry and Compulsive, Impulsive and Autism Spectrum Program, Albert Einstein College of Medicine and Montefiore Medical Center, Bronx, NY, USA

12. Department of Psychiatry, Bellvitge University, Hospital-IDIBELL, University of Barcelona, Cibersam, Barcelona, Spain

13. Department of Psychiatry, University of Cambridge, Cambridge, UK

14. Cambridge \& Peterborough NHS Foundation Trust, Cambridge, UK

15. Department of Psychiatry and Mental Health at the University of Cape Town and South African MRC Unit on Risk \& Resilience in Mental Disorders, Cape Town, South Africa

16. Department of Psychiatry and Behavioural Neurosciences, McMaster University, Ontario, Canada 
17. Sackler Medical School, Tel Aviv University, and Chaim Sheba Medical Center Tel Hashomer, Tel Aviv, Israel

18. Department \& Institute of Psychiatry, University of Sao Paulo Medical School, Sao Paulo, Brazil

19. INS, Institute of Neuroscience, Florence, Italy

20. Dipartimento di Medicina Clinica e Sperimentale, Section of Psychiatry, University of Pisa, Italy

21. Rita Levi Montalcini Department of Neuroscience, University of Turin, Italy

22. Obsessive, Compulsive, and Anxiety Spectrum Research Program, Institute of Psychiatry, Federal University of Rio de Janeiro, D'Or Institute for Research and Education Rio de Janeiro, Brazil; and Turner Institute for Brain and Mental Health, School of Psychological Sciences, Monash University, Melbourne, Australia

23. Department of Biomedical and Neuromotor Sciences, Alma Mater Studiorum University of Bologna, Bologna, Italy

24. San Luigi Gonzaga University Hospital, Orbassano (Torino), Italy

25. Western Sydney Area Health Service - Obsessive-compulsive and related disorders service, Blacktown Hospital, Blacktown, Sydney, Australia.

26. Department of Child and Adolescent Psychiatry and Psychotherapy, University Hospital of Psychiatry Zurich. University of Zurich, Switzerland

27. RUG and UMC Groningen, Department of Psychiatry, GGZ Drenthe Mental Health Institute, the Netherlands

28. Dept. of Psychiatry, Massachusetts General Hospital, Harvard Medical School, USA

29. Department of Neuroscience, Psychology and Behaviour, University of Leicester, UK

30. Department of Psychiatry, VU University Medical Centre, Amsterdam, the Netherlands.

Corresponding author: Naomi A Fineberg, Hertfordshire Partnership University NHS Foundation Trust, Rosanne House, Welwyn Garden City, UK, AL8 6HG. Tel. 0044 (0) 1707 364055, email naomi.fineberg@nhs.net

Word count: Abstract $=244$, Body $=9594$ 


\section{Abstract}

Obsessive-compulsive disorder (OCD) is common, emerges early in life and tends to run a chronic, impairing course. Despite the availability of effective treatments, the duration of untreated illness (DUI) is high (up to around 10 years in adults) and is associated with considerable suffering for the individual and their families. This consensus statement represents the views of an international group of expert clinicians, including child and adult psychiatrists, psychologists and neuroscientists, working both in high and low and middle income countries, as well as those with the experience of living with OCD. The statement draws together evidence from epidemiological, clinical, health economic and brain imaging studies documenting the negative impact associated with treatment delay on clinical outcomes, and supporting the importance of early clinical intervention. It draws parallels between OCD and other disorders for which early intervention is recognized as beneficial, such as psychotic disorders and autism spectrum disorders, as well as impulsive-compulsive disorders associated with problematic usage of the Internet, for which early intervention may prevent the development of later addictive disorders. It also generates new heuristics for exploring the brain-based mechanisms moderating the 'toxic' effect of an extended DUI in OCD. The statement concludes that there is a global unmet need for early intervention services for OC related disorders to reduce the unnecessary suffering and costly disability associated with under-treatment. New clinical staging models for OCD that may be used to facilitate primary, secondary and tertiary prevention within this context are proposed.

\section{Key words}

obsessive; compulsive; OCD; early intervention; duration of untreated illness; staging 


\section{Vignette}

I first had OCD symptoms when I was 17. Intensely worried and not daring to speak to anyone about my disturbing intrusive thoughts, I hesitated and then went to see a psychologist for help. Unfortunately, she failed to discuss the diagnosis of OCD with me and put me through an extensive program of Freudian psychoanalysis, which only made me worse.

The OCD waxed and waned for several years, until I had a major relapse around the birth of my second son, when I was 30. This time, a friend lent me a book, which led me to a self-diagnosis of OCD.

I immediately went to my GP, who agreed with my diagnosis. But with waiting lists too long for talking therapies, I went private. I saw a specialist in cognitive behavioral therapy (CBT) who took me through a program of exposure and response prevention that eventually helped me overcome that particular relapse.

I've had many relapses since then, sometimes with crippling depression that has left me suicidal. Medications - particularly clomipramine - have helped with the depression, while subsequent courses of CBT have helped me manage my OCD.

Had I got a correct diagnosis and treatment from the start, I'm convinced my subsequent relapses wouldn't have been as bad. That's why I believe that early diagnosis and treatment are key. 


\section{Introduction}

Obsessive-compulsive disorder (OCD) represents one of the most common, chronic, costly and burdensome brain disorders, in terms of the personal impact, direct treatment-related costs and the indirect costs related to lost productivity (Hollander et al 2016). Commonly emerging in childhood or adolescence (Dell'Osso et al., 2016a), the disorder is associated with substantial distress, treatmentseeking activity, functional disability and suicidality (Carmi et al., 2019). Evidence-based treatments include cognitive behaviour therapy (CBT) and pharmacological treatment with serotonin reuptake inhibitors (Skapinakis et al., 2016a). In cases where family accommodation of symptoms appears problematic, specific involvement of family members in the treatment plan can be helpful. Although studies suggest that recovery can be a realistic goal for a subgroup of the OCD population (Burchi et al., 2018), 'real world' clinical outcomes are often disappointing. Relapse rates are high and fewer than $40 \%$ of treatment-seeking adults with OCD are reported to achieve a sustained remission when followed up long-term (Eisen et al., 2013, Skoog G and Skoog I, 1999). In a thirty years follow-up study of largely nontreatment seeking cases of obsessive-compulsive disorders and syndromes, the median duration of OCD was $16 y$, roughly one-third of OCD cases did not remit and a poorer prognosis for remission was seen in those with more severe or longer duration of illness, psychiatric comorbidity and those seeking professional help (Fineberg et al 2013c)).

OCD in childhood clinical samples also shows high rates of persistence despite treatment provision (Stewart et al., 2004; Zellmann et al., 2009). In the meta-analysis of childhood studies by Stewart and colleagues (2004), the pooled mean persistence rates were $41 \%$ for full OCD and $60 \%$ for full or subthreshold OCD. Epidemiological studies also suggest moderate stability of OC symptoms in children, with genetic as well as environmental factors contributing to persistence and remission (van Grootheest 
et al., 2007). In the study of Mancebo and colleagues (2014), a shorter latency to initiation of OCD treatment was associated with faster onset of remission. Indeed, converging evidence from multiple centres indicates that a longer duration of untreated OCD (as opposed to an early onset of illness) is associated with increased clinical comorbidity and functional disability, as well as significantly poorer treatment-related clinical outcomes including treatment response and remission (Dell' Osso et al., 2013a; 2016a, Albert et al., 2018a (in submission), b; Rufer et al., 2005).

Most cases of OCD arise before the age of 18y (Fineberg et al., 2013, Ruscio et al., 2010, Rapoport et al., 2000, Dell'Osso et al., 2016a), and the duration of untreated illness (DUI) for OCD remains one of the highest for any severe mental disorder (Altamura et al., 2010). Most adults with OCD have been suffering for more than 10 years before effective treatment is initiated (Garcia-Soriano et al., 2014, Albert et al., 2018a). In the case of children and adolescents, the diagnosis is also often missed (Rapoport et al., 2000), and the lag between the onset of OCD and ascertainment of the diagnosis is reported by some specialized centres to lie at two to three years (Geller et al., 2000). The average DUI also exceeds two to three years (Walitza et al., 2008; Zellmann et al., 2009). This is a relatively long delay, given that the average patient age in these samples was only 13 years.

Brain imaging has identified neuro-circuitry abnormalities associated with OCD appearing to evolve as transition from childhood to adulthood occurs. In children and adolescents with $O C D$, similar altered functional activations in the same brain regions of affective and cognitive cortico-striatal-thalamic (CST) circuits exist as in adult OCD patients (Brem et al., 2012). However, a large mega- and meta-analysis of imaging data from multiple sites found that the brain alterations became more heterogeneous and complex with increasing age, suggesting that $O C D$ is underpinned by complex, nonlinear 
neurodevelopmental mechanisms (Boedhoe et al., 2018, Boedhoe et al., 2017). Arguably, early intervention, bringing with it the potential for improved symptom-control, could help to interrupt the progression of such brain-based changes, though as yet we do not have imaging data to support this.

By missing out on timely, effective treatment, the majority of people with OCD can be expected to endure many years of chronic or relapsing illness. Intervention aimed at delivering early accurate detection and diagnosis accompanied by targeted evidence-based interventions, could be expected to produce more clinically and cost effective outcomes (Brakoulias et al., 2018). Using similar arguments, early intervention teams for psychosis are well-established in America, Europe and Australasia (Edwards et al., 2002, NICE UK https://www.england.nhs.uk/mentalhealth/wp-content/uploads/.../eipguidance.pdf)).

This consensus statement, representing the views of an international group of expert clinicians, scientists and people with lived experience of OCD, draws together evidence suggesting that greater emphasis on targeted early intervention, appropriately delivered within mental health services, is also required for people suffering with $O C D$. We propose new staging models for $O C D$, including prototypical criteria for early prodromal stages of the illness, as one of the first steps toward the development of early intervention strategies. We hope this statement will have a positive influence on clinicians' practice. We note, for example, results of a survey among Danish clinicians suggesting that clinical recommendations on assessment and treatment for children and adolescents with OCD could be translated into positive clinical outcomes (Nissen and Thomsen, 2008). 


\section{Methods}

In developing this consensus statement, a working group was selected from among the members of the European College of Neuropsychopharmacology (ECNP) Obsessive Compulsive and Related Disorders Research Network (OCRN), the International College of Obsessive Compulsive Spectrum Disorders (ICOCS) and the World Psychiatric Association Anxiety and Obsessive Compulsive Disorders Section. The group comprised expert clinicians, including child and adult psychiatrists, psychologists and neuroscientists, including those working in high, low and middle income countries, and included an individual with the experience of living with OCD. The group performed a narrative review of the scientific literature pertaining to the cost and burden of OCD across the lifespan, the duration of untreated illness (DUI) and its impact on health and wellbeing outcomes, and the potential role of early intervention, from various perspectives reflecting their experience and expertise. After several iterations, a draft was circulated among the extended membership of the aforementioned organisations and further comments were integrated. A final document was presented, discussed and provisionally endorsed, subject to minor amendments, by around 40 delegates in a symposium programmed within the $14^{\text {th }}$ Annual Scientific Meeting of the ICOCS, held in association with the ECNP OCRN, Barcelona, October $10^{\text {th }} 2018$.

\section{Epidemiology of OCD}

OCD has an estimated lifetime prevalence of $2-3 \%$ under DSM-III, DSM-III-R and DSM-V criteria (Robins et al., 1984; Weissman et al., 1994, Ruscio et al., 2010). Some epidemiological surveys of US and European citizens, using diagnostic instruments aligned with the DSM-IV, produced more conservative estimates of lifetime prevalence of respectively 1.6\% (Kessler et al., 2005a) and 0.8\% (Wittchen et al., 2011). Another epidemiological survey (Kessler et al., 2011), possibly capturing a broader spectrum of 
cases, estimated the lifetime prevalence at $5.8 \%$ and $6.2 \%$ in low and high income countries respectively. Indeed, other epidemiological surveys have estimated the prevalence of subclinical OC syndromes at between 7 - 25\% (Bebbington et al., 1998, Fullana et al., 2009; Fullana et al., 2010; Fineberg et al., 2013a). Fullana and colleagues (2009) analysed the 20-year prospective Dunedin study of an unselected birth-cohort aged 11 to 32 years. Consistent with the US National Comorbidity data (Ruscio et al., 2010), DSM-IV OCD was reported in $2.3 \%$ of the sample at age 26 years and $1.8 \%$ at age 32 years, whereas sub-syndromal obsessions and compulsions, affecting up to $25 \%$ of the cohort, were also found to be associated with significant impairment and help-seeking behaviour.

Obsessions and compulsions often have their roots in childhood and, if persistent, are associated with psychosocial impairment (Fullana et al., 2009) including interference, risk of comorbidity and helpseeking, irrespective of whether or not the diagnostic threshold for OCD is met. According to a UK survey of children and adolescents (Heyman et al., 2001), OCD was rare in younger children and increased towards adult rates, around $2 \%$, by puberty. Moreover, the presence of obsessive-compulsive (OC) symptoms at 11 years predicted a high risk of OCD and more severe symptomatology in adulthood. Thus, sub-syndromal OC symptoms are common, associated with distress or impairment, may presage the onset of OCD and therefore represent a potential target for intervention.

The most common age at onset of OCD was historically reported to occur around $20-30$ years (Pollitt 1957; Ruscio et al., 2010, Altamura et al., 2010). However, there appear to be two peaks of incidence, one with a pre-adolescent onset (mean age 9-10 \pm 2.5 years, Geller et al.,1998; mean age 11 years, Taylor, 2011), and another in early adulthood (mean age 23 years, Taylor, 2011). Approximately threequarters of cases (76\%) included in a meta-analysis demonstrated an early onset of OCD (Taylor, 2011). Other studies report an infrequent onset after 30 years (Grant et al., 2007). In a thirty year prospective epidemiological study (Fineberg et al., 2013a), although full OCD could not be identified before 10 years 
of age, sub-threshold cases were retrospectively reported as early as two years of age, around two thirds of OCD cases had emerged by the age of 22 years, and no new cases of OCD developed after age 37 years. There was a clear increase in professional treatment related to OC severity. Lesser OC symptomatology tended to show an earlier age of onset than $O C D$, and $O C D$ was frequently preceded by sub-diagnostic OC-symptoms. Suicidality and serious workplace problems were substantially associated with OC symptomatology, notably with $O C D(O R=4.10$ and 4.61 for suicidality and workplace problems, respectively). However, similar to the childhood data (Fullana et al., 2009), those with lesser OC symptomatology, comprising $20 \%$ of the community sample, also reported significant suffering.

Whereas OCD is over-represented in females in community studies (around 1.5:1), males are overrepresented in those with early onset of illness (Fineberg et al., 2013a). Evidence from studies on convenience samples suggests that early onset $O C D$ is associated with a number of distinguishing features, of relevance for clinical intervention, including comorbidity with neurodevelopmental disorders such as tic disorder and attention deficit hyperactivity disorder (ADHD) and familial clustering suggesting a greater genetic contribution (Walitza et al., 2008, Walitza et al., 2010, Taylor 2011). Indeed, in some studies, early-onset OCD has been associated with specific gene variants of serotonergic, dopaminergic and glutamatergic receptors and synaptic brain related genes, neurotrophic and transcription factors (Walitza et al., 2014, Grünblatt et al., 2017). Symmetry, ordering and sexual or religious symptoms are also associated with early-onset OCD (Labad et al., 2008), possibly linked to comorbidity with tic disorders and tic-specific symptoms. Later onset cases include females developing OCD in pregnancy, after parturition or miscarriage, where the diagnosis is often missed (Williams and Koran, 1997). Prospective studies in postpartum females have shown an incidence of OCD ranging from $4 \%$ to $11 \%$, with some evidence suggesting avoidant and obsessive-compulsive personality traits 
predicted postpartum risk (House et al., 2016). Thus, early onset and later onset OCD seem to be distinguishable in terms of gender, comorbidity and genetics, and this may be of relevance for planning therapeutic intervention.

\section{The burden and costs of untreated OCD}

When making medical and policy decisions, including the introduction of early interventions and services, the burden of a disorder in terms of mortality, comorbidity, disability and effects on the quality of life, as well as the cost of interventions and their effectiveness, are of paramount importance. Although health economic studies in OCD are still limited, some data are available, helping to shed light on this matter.

A strong consensus of scientific opinion emphasizes the negative impact of OCD on the quality of life, wellbeing and global functioning of affected patients and their related caregivers (Macy et al., 2013). A number of studies have examined quality of life (QoL) in OCD and several comprehensive reviews have been carried out (Coluccia et al., 2016; Macy et al., 2013; Subramaniam et al., 2013; among others). Patients with OCD show a poorer QoL than healthy controls and the population in general. Further, when OCD has been compared with other mental or physical conditions, some studies, although not all, have found that the effects of OCD on QoL are similar to those of serious mental illnesses such as schizophrenia (Macy et al., 2013; Subramaniam et al., 2013). The QoL domains most affected in OCD include social relationships, including emotional and psychological components. Physical domains, although impaired, are usually less affected. 
Two key factors reported to influence QoL in OCD include disease severity and comorbidity. The association between OCD severity and QoL impairment is seen to affect even subclinical samples (Fullana et al., 2009, Fineberg et al., 2013a). Comorbid conditions, such as anxiety disorders, mood disorders or OC related disorders (OCRDs), which are very frequent in OCD patients, have a highly significant impact on lowering QoL. Importantly, treatment studies have shown that improvement in OCD is associated with an increase in QoL. Hollander and colleagues (2010) showed that disability and QoL significantly improved in patients showing a positive symptomatic treatment-response, and was significantly better compared to non-responders or those who experienced a relapse. Therefore, $O C D$, even at subclinical levels, involves a substantial decrease in QoL, which significantly improves with effective treatment and improvement of the condition.

Studies focusing on disability have also demonstrated the substantial impact of OCD. Wittchen and colleagues (2011) examined the disability adjusted life years lost (DALY) associated with a broad range of mental and neurological illnesses in Europe. Although the study reported a lower prevalence of OCD (0.7\%) than is usually reported in epidemiological studies, OCD accounted for 329,684 DALYs, which means a rate of 7.9 DALYs per 10,000 persons, i.e. higher than that reported in epilepsy (6.9), although lower than that of unipolar depression (10.3), which showed the highest disability. Indeed, the high rates of comorbidity usually existing between OCD and depression suggests that those with both conditions, who may show even higher levels of disability than those with 'pure' illness, might have been included in the depression group only, thus underestimating the true impact of OCD. Rates of under-employment ranging from $22 \%$ to as high as $38 \%$ have been reported among OCD subjects in community and clinical 
samples (Mancebo et al., 2008). Early intervention could thus be expected to reduce burden and costs of $\mathrm{OCD}$, for example, by treating frequently co-occurring depression early.

Although research into the costs of treated and untreated $O C D$ is scarce, the existing data emphasise the significant indirect costs of OCD, such as loss of employment productivity, and the highly cost-effective impact of effective treatment (Hollander et al., 2016). For example, historical data estimating the 1990 total costs of OCD in the USA found that indirect costs, reflecting lost productivity of individuals suffering from residual OCD, represented $74 \%$ of the total economic cost of OCD (Dupont et al., 1995). Another analysis by Knapp and colleagues (2002), which examined health service utilization, including mental health expenditure, inpatient hospitalization and ambulatory services, other formal care services, lost employment and education, family and caregiver impact, mortality, and transfer payments, concluded that the economic consequences of OCD were widespread, long lasting, and often profound, involving not only the direct costs of treatments and health services utilization, but also the indirect effects on personal income, the ability to work, productive contributions to the national economy and impoverishment of quality of life.

Preliminary studies using health economic modelling have suggested that the treatment of OCD using standard pharmacological or psychological therapies, or their combination, is cost-effective. Two analyses (Skapinakis et al., 2016b, Fineberg et al., 2018) estimated that SSRIs represented the most cost-effective option, whereas the other (National Institute for Health and Clinical Excellence, 2006), estimated that the combined option was the most cost-effective. Further studies designed to test real-world effectiveness and cost-efficiency are indicated to confirm the relative cost effectiveness of all standard treatment modalities with greater certainty (Fineberg et al., 2018). 


\section{Duration of untreated illness in OCD}

Lack or delayed initiation of treatment are thought to play a relevant role in the overall burden of OCD. Over the past several years, research has investigated the DUI, defined, in most investigations, as the interval between the onset of a specific psychiatric disorder and the administration of the first pharmacological treatment at standard dosages and for an adequate period of time, in adherent subjects with OCD (Dell'Osso and Altamura, 2010).

In those studies taking an epidemiological approach, the DUI in OCD has been consistently demonstrated to count among the longest for any psychiatric disorder - in recent years ranging between seven and ten years in adults (Altamura et al., 2010; Dell'Osso et al., 2013b; Poyraz et al., 2015, Albert et al., 2018a; Benatti et al., 2016), and exceeding two to three years in children (Walitza et al., 2008; Zellmann et al., 2009). These estimates are alarming, not only for the overall duration (in the case of children, constituting almost one quarter of their lifetime, assuming a median age of onset of 11 years), but also because in adults the DUI accounted for approximately half of the entire duration of OCD. This implies that patients spent half of their illness either untreated or receiving ineffective treatment (Viswanath et al., 2011; Dell'Osso et al., 2015, Poyraz et al., 2015). Another survey of child and adolescent referrals to a centre specialising in treating therapy-resistant OCD found that fewer than half of the referred patients (44.8\%) had received adequate first-line treatment with CBT or SSRI before receiving care from this tertiary care center (Nair et al., 2014). Indeed, young people appear poor at accessing timely treatment and 'technical treatment failure' represents a common cause of apparent refractoriness (Micali et al., 2010). Importantly, the DUI in children and adolescents is reported to constitute one of the strongest predictors of OCD persistence over time (Micali et al., 2010). 
A number of factors have been identified as contributing to the high DUI, including biological (genetic loading), familial/cultural (stigma-related attitudes), psychological (different illness phenotypes and their relationship with secretiveness (Viswanath et al., 2011, Dell'Osso et al., 2015, Benatti et al., 2016); believing that OCD symptoms do not represent illness (Poyraz et al., 2015)) and societal factors (poor access to psychiatric services with expertise in the diagnosis and management of OCD (Menchon et al., 2016)). A recent Italian study showed a progressive, statistically significant reduction of the latency to first pharmacological treatment emerging across subsequent epochs of onset in patients with psychiatric disorders including OCD (Dell'Osso et al., 2016b). In other words, patients with a more recent versus a more distant onset of $O C D$ waited less time before receiving a guideline-recommended treatment. Moreover, the shortening of the DUI was related to improved access to a psychiatrist, as opposed to the GP or another clinician, implying that if better access to appropriate clinical services, in particular to a psychiatrist, is provided, the DUI can be reduced.

Specific clinical implications have been linked with a longer DUI. For instance, a DUI exceeding 24 months was associated with a poorer response to pharmacological treatment (Dell’Osso et al., 2010, Albert et al 2018a (see below)). On the other hand, greater severity of OCD was associated with a shorter DUI (Dell'Osso et al., 2017), probably because, as has been demonstrated elsewhere (e.g. Fineberg et al., 2013a), those who are more severely unwell (and/or their caregivers) are more likely to seek help and receive treatment sooner, compared with those with a more chronic but fluctuant form of illness. A longer DUI may also be associated with greater family accommodation of symptoms, thereby counteracting the goals of exposure and response prevention, promoting treatment resistance (Albert 
et al., 2017). Moreover, the effect of accommodating to OCD in a child or young person has a profoundly damaging effect on family relationships and the health of family members/caregivers (Peris et al., 2008).

Another negative consequence of a long duration of untreated OCD is the development of a greater burden in terms of associated psychiatric or general medical conditions (Aguglia et al., 2018). Persistent avoidance of medical consultations associated with untreated fear of contamination, for example, may lead to failure to achieve appropriate diagnosis and treatment for medical problems (Albert et al., 2010), adding further burden to the existing psychiatric disorder. Anxiety and affective disorders are found to occur in over $60 \%$ cases (Ruscio et al., 2010). Psychiatric comorbidity is associated with increased severity and chronicity (Fineberg et al., 2013b) as well as higher levels of functional impairment, distress and suicidality (Angst et al., 2005). While different comorbid disorders impact variously on distress levels and psychosocial impairment, largely characterised in comorbid OCD by damage or a breakdown in close relationships, bipolar disorder, unipolar depression and alcohol misuse in OCD have additionally been associated with occupational role impairment and/or unemployment (Fineberg et al.,2013b). People with $O C D$ and $O C$ syndromes are also more likely to seek treatment if they suffer with a comorbid psychiatric disorder. Severe, chronic illness is associated with high direct and indirect healthcare costs and high levels of hospitalisation (Drummond, 1993). Around $25 \%$ of these cases attempt suicide (Kamath et al., 2007).

The epidemiological and clinical correlates of the DUI in OCD are of particular importance in the context of interventional strategies and services. DUI represents a modifiable factor, and intervention programs aimed at promoting early diagnosis, and bridging the gap between child and adult psychiatrists, are likely to reduce the latency to effective treatment (Dell'Osso et al., 2013c), and thereby reduce the costs 
and consequences of untreated illness. In addition, educative public-health programs aimed at promoting early OCD diagnosis should be disseminated to general practitioners and consideration given to translating scientific knowledge into information easily available for the general population, increasing the recognition of OCD by the lay public and primary care clinicians.

\section{Early Intervention Targets for OCD}

Despite the availability of effective treatments for OCD (Hirschtritt et al., 2017), the treatment gap (difference between individuals with $O C D$ needing treatment and those actually receiving it) was estimated, in Europe, to stand at 25\% of cases in 2004 (50\% approximately in the world) (Kohn et al., 2004). The proportion of subjects not being treated worldwide in more recent epidemiological studies was estimated to vary between 22 and 92\%, with 38-to-90\% of individuals not even seeking treatment or advice (Garcia-Soriano et al., 2014). In those patients with OCD receiving treatment, the extended DUI can be attributed to long delays in actively seeking help (e.g. the mean interval between disorder onset and help seeking behavior has been quantified as approximately 7 years (Albert et al., 2018a)). Educational campaigns presenting $O C D$ as an illness that can be cured and resources to improve access to mental health services could in the near future shorten the delay in seeking treatments.

However, the interval between help seeking and receiving an adequate treatment for OCD is also significant (approximately 2 years for pharmacological treatment (Strengler et al., 2013; Albert et al. 2018a)). This means that there is difficulty for physicians and/or mental health professionals in recognizing and diagnosing OCD appropriately (high rates of OCD symptom misidentification by mental health professionals were found (Glazier et al., 2013)), or in prescribing or offering an adequate treatment (it 
may be that psychological therapies other than CBT with exposure and response prevention are applied, or that antidepressants other than clomipramine or SSRIs are prescribed, or for less than the required 12 weeks, or at sub-therapeutic doses). There is thus a strong need for early recognition and appropriate diagnosis for OCD.

The importance of shortening the DUI becomes evident when examining treatment-response rates. In patients with OCD, response rates are significantly reduced when the DUI is longer, and this is even more evident when considering the first ever adequate treatment (e.g. from $70 \%$ to $40 \%$ for those with a DUI $\leq 24$ months versus $>24$ months) (Dell'Osso et al., 2010; Albert et al., 2018a). This may imply that the longer the DUI the greater the "biological or psychosocial damage" associated with the duration of severe symptoms. It may be speculated that the DUI in OCD promotes neuroprogression or neurodegeneration, as hypothesized for psychosis (Anderson et al., 2014). Studies demonstrating an association between longer duration of OCD and either reduced hippocampal and amygdalar volumes (Atmaca et al., 2008) or reduced $\mathrm{N}$-acetyl aspartate among other neurochemical measures in several cerebral areas (Gnanavel et al., 2014) provide some evidence in favor of a "neuroprogressive or neurodegenerative" hypothesis. Indeed, an as yet un-replicated study found that in those OCD patients who relapsed after discontinuation of drug, response rates were lower following re-instatement of the same pharmacological treatment (same compound given at exactly the same dosage) compared to the initial response rates. These findings have been interpreted to suggest that relapse in OCD adversely affects treatment outcomes (Maina et al., 2001).

\section{Early Intervention for Children and Adolescents with OCD}


It would seem obvious that any disorder, including OCD, deserves early intervention to alleviate suffering and abbreviate functional impairments associated with illness. However in youth, this is particularly crucial due to several specific factors.

First, the unique cognitive, academic and social developmental tasks of childhood and adolescence are concentrated into a relatively few years. If these developmental milestones are disrupted, it may have lasting consequences well beyond childhood, and perhaps even a lifelong effect, with an altered educational, professional or social trajectory. Youth are therefore particularly vulnerable to the effects of mental illness, due to the cascading effects of functional impairments and in no other population does early intervention hold more promise for reducing chronicity, and the economic and social burdens associated with OCD. In addition, children are frequently less able to articulate their obsessional thoughts or to have the maturity and ego-function to recognize their obsessional mental experiences as aberrant, as something different from normal self, so that insight may be lacking and obsessions can only be inferred by (adult) observers of ritualistic behaviour (Storch et al., 2014).

Next are the illness-specific factors associated with OCD in youth that are not seen as frequently in adults and that may require specialist knowledge and intervention. These include symptom-specific presentations or symptom dimensions in young patients (Geller et al., 2001b, Stewart et al., 2007), a unique and developmentally-specific profile of common comorbid psychiatric disorders (Geller et al., 2001b), a unique pattern of neurocognitive deficits (Geller et al., 2017), increased familial aggregation of early-onset OCD (Rosario-Campos et al., 2001, Walitza et al., 2010, Taylor, 2011), high rates of family accommodation as a consequence of children being embedded in family units and perhaps environmental or epigenetic influences that occur at a sensitive period of neural maturation (Geller et 
al., 2007). Recently it was shown that serotonin transporter-gene methylation levels were significantly higher in children and adolescents with OCD compared to controls and adult patients with OCD. Furthermore, morning awakening salivary cortisol levels positively correlated with methylation levels (Gruenblatt et al., 2018). Together, these findings have led some to posit a developmental subtype of OCD affecting youth and this is partly reflected in the DSM-5 which specifies a tic-related form of OCD with early onset that is male predominant, with different patterns of familial inheritance, comorbidity and course (American Psychiatric Publishing, 2013).

Obsessional anxiety frequently follows developmental themes that may be difficult to dissociate from normal childhood development (Geller et al., 2000). In childhood, evolving autonomy and separation often lead to fears of harm to attachment figures and may produce behaviours that mimic separation anxiety but are driven by OCD (Storch et al., 2011), while in adolescence, tensions around sexuality and moral and religious development frequently find their way into obsessional content (Geller et al., 2000).

High rates of psychiatric comorbidity also present clinical challenges. More than half of children diagnosed with OCD will meet criteria for another psychiatric diagnosis, even in epidemiological samples, and rates as high as $80 \%$ are reported in clinically ascertained cohorts. In comorbid OCD, medication treatment approaches often diverge, producing a challenge from a psychopharmacological perspective, since OCD cannot be treated in isolation. Each comorbid disorder presents risk for longerterm outcome in affected children (Walitza et al., 2008). Overlap with autism spectrum disorders (ASD) is common and can present diagnostic and treatment challenges particular to this age group that must necessarily include family and educational interventions (Volkmar et al., 2014). Clinical studies have also demonstrated comorbid impulse-control problems such as tic disorders and ADHD, occurring alongside 
anxiety symptoms, in subsets of children with OCD, co-segregating in families and often presenting a classical "triad" diagnostic picture (Geller et al., 2007). Impulse-control problems continue to feature in cases of adult $O C D$, while preclinical research has identified neuropsychological markers of inhibitory dyscontrol in OCD families (Chamberlain et al., 2005). Prospective studies, beginning in childhood, investigating the role of latent markers of the association between early-onset impulse-control disorders and OCD, may elucidate a specific OCD subtype (Kessler et al., 2011). A 'baby sibs' research programme for families with an existing child with $O C D$, following-up at risk siblings from birth to identify early signs and biomarkers indicating a role for early intervention, represents a rational future step.

Finally, treatment approaches and outcomes in childhood OCD appear to be somewhat varied, and possibly more optimistic, compared with those seen in adult patients. For example, family therapy techniques aimed at challenging the unhelpful accommodation of OCD symptoms may be particularly helpful in the younger age group (Peris et al., 2017). In a meta-analysis by Stewart and colleagues (2004) the persistence rate for full OCD was around $40 \%$ and for subthreshold OCD was around $60 \%$. Randomized controlled pharmacological trials have been hampered by very high placebo response rates in children (Geller et al., 2003). Compared to medication, CBT in youth has undergone less controlled investigation versus psychological placebo (Skapinakis et al., 2016), but is acceptable to parents and seems particularly effective when delivered in systematized formats that include family participation (Peris et al ., 2017). Further, the recent Nordic long term treatment study (NordLOTS) (Hojgaard et al., 2017) suggests that, with extended CBT protocols tailored to outcome, about two thirds of children will have good outcomes with response and remission. A further study found that when children and adolescents were first randomized to SSRI or group CBT, followed by a second randomization to switch 
or add the other treatment for non-responders, significant improvement occurred over time in all groups, regardless of the sequence of treatments (Fatori et al., 2018).

In summary, youth with OCD present particular challenges but also a hopeful outcome picture when early intervention can be applied in standardized way that can mitigate the prolonged harmful effects of untreated illness (Storch et al., 2018). No prospective controlled longitudinal study has examined whether effective early intervention reduces long-term disability from OCD (or impact on a child's ability to meet developmental milestones). Although the question as to whether or not early intervention produces better outcomes ideally requires testing in a prospective randomised controlled trial, it is unlikely, for ethical reasons, that a study requiring adequate treatment to be withheld would ever be undertaken. Nevertheless, we judge many of the arguments supporting early intervention for OCD in childhood (alleviating suffering, optimising the navigation of critical developmental milestones, counteracting negative effects of family accommodation, better treatment outcomes compared to adulthood $\mathrm{OCD}$ ) to be strong and strategies for early intervention should be incorporated into existing standards of care programmes (such as Menchon et al., 2016).

\section{Staging models for OCD}

"Illness staging" is a commonly used technique in several medical disciplines, helping to predict course or prognosis and optimize treatment (Berk et al., 2017). Staging models in psychiatry have mainly been applied to schizophrenia, bipolar disorder and depression (de la Fuente-Tomas et al., 2018). Based on the proposition that psychopathology advances predictably, they propose an "at-risk" or latency stage, a prodromal stage with the odds of progressing to a first clinical threshold episode, and a full illness stage 
with the potential to revert or progress to late or end-stage manifestations. Such models imply the presence of an active disease process that, if not remediated, leads to neuro-progression, a more damaging disease course and functional deterioration (Berk et al., 2017). Staging models also imply that stage-specific treatments may be successful in impeding illness progression as well as targeting symptom reduction. These treatment approaches range from 'prevention' for at-risk individuals, to early intervention approaches for prodromal and newly diagnosed individuals, complex combination therapy for recurrent or resistant illness, and palliative-type approaches for those with chronic, late stages of illness (Berk et al., 2017).

A similar staging model could be proposed for OCD and other OCRDS. The utility and validity of such a model would depend on evidence linking the different stages to clinical outcome, treatment response and neurobiological measures. A substantial proportion of the population (estimated at $21 \%$ and $28 \%$ in the studies by Ruscio et al., 2010 and Fineberg et al., 2013a) report subthreshold symptoms that may represent the first 'at risk' stage. These individuals do not meet the full diagnostic criteria for OCD, and in the main do not progress to full blown OCD, but do nevertheless experience some harms (Fullana et al., 2009, Fineberg et al 2013a). Conversely, cases of full-blown OCD are usually preceded (or followed by) sub-diagnostic OC-symptoms (Fineberg et al., 2013a). One study indicated that the earliest symptoms shown by OCD patients belong to the symmetry and ordering dimension (Kichuk et al., 2013). These symptoms may be of particular relevance for identifying those most at risk of developing OCD. Appropriate methods of clinical intervention for these cases remain a matter for further research, as traditional treatments (including SSRI, CBT) may not be appropriate. In the case of at risk children, as a general principle, it would seem wise to educate parents not to accommodate OC symptoms and how to avoid undue antagonism. 
As described above, OCD develops in vulnerable cases, including those with prodromal OC symptoms, through the actions and interactions of specific inherited and environmental risk factors, such as family history of OCD, tic, or exposure to trauma or, in the case of young women, pregnancy and childbirth. Individuals with subthreshold OC symptoms or traits (especially symmetry, ordering) alongside exposure to these factors may therefore represent the second stage i.e. "ultra-high risk' mental states, for whom early intervention in the form of careful monitoring to prevent progression to full blown OCD would be relevant. There are thus arguments to actively screen for OC symptoms and syndromes in appropriate high risk groups, such as within maternity services, focussing on ultra-high risk parents and children.

OCD represents the next stage, manifesting usually in childhood as the first clinical episode and requiring intervention with evidence based treatments such as CBT and SSRI. Further stages of illness could be conceptualised as responsiveness or resistance to different interventions (CBT, SSRI, antipsychotic) staged according to evidence - based algorithms (e.g. Fineberg et al., 2015).

The establishment of a staging model would generate testable hypotheses for onwards validation in longitudinal naturalistic trials, addressing gaps in knowledge e.g. the proportion of cases staged as medium or high risk eventually developing $O C D$ and the predisposing or precipitating factors linked to transition to the full disorder, as well as interventional studies e.g. the effectiveness of low intensity CBT interventions in sub-syndromal groups in relieving distress or preventing conversion into OCD.

\section{Immunological Factors and Early Intervention}


The role of the immune system and inflammation in OCD pathophysiology emerged in the early nineties, when an autoimmune pathophysiology hypothesis was proposed for several case series of OCD characterized by pre-pubertal acute onset, episodic course and concurrent neurological abnormalities such as choreiform movements occurring or exacerbating after exposure to infection (Swedo et al., 1998). This syndrome, initially termed pediatric autoimmune neuropsychiatric disorder associated with group A beta-hemolytic streptococcus (GABHS) (PANDAS), was renamed pediatric acute neuropsychiatric syndrome (PANS), since evidence highlighted the fact that several agents other than streptococcus might be involved (Chiarello et al., 2017). The mechanism hypothesized for PANS involves cross-reactivity between gangliosides in basal ganglia neurons with the GABHS and/or other agents' cells, as is the case for the Sydenham's chorea (Chiarello et al., 2017). Indeed, there are some reports of anti-basal ganglia antibodies in the serum of PANDAS/PANS cases (Pearlman et al., 2014). Also, evidence of inflammatory and immune system abnormalities in the form of higher rates of total monocytes and CD16+ monocytes were reported in pediatric OCD (Rodríguez et al., 2017).

Inflammatory biomarkers are important, as they may identify a potentially remediable prodromal stage of early onset $O C D$. The relevance of neuro-inflammation and/or autoimmunity in OCD is not necessarily limited to subsets of pediatric and acute onset forms of OCD, and could be also relevant for adults. Indeed, recent studies showed the presence of inflammation in the cortico-striatal-thalamo-cortical circuit (Attwells et al., 2017) and the presence of greater plasma levels of IL-2, IL-4, IL-6, IL-10 and TNF- $\alpha$ levels in adult OCD patients compared to controls (Rao et al., 2015), as well as higher rates of anti-basal ganglia antibodies (Pearlman et al., 2014, Nicholson et al., 2012). Systemic autoimmune diseases are reported to be associated with an increased risk of OCD (Wang et al., 2018). Other recent evidence showed that the gut-microbiota may have a potential role in brain inflammation and PANDAS/PANS 
cases (Quagliarello et al., 2018). Thus, neuro-inflammation and autoimmunity seems to be involved in several forms of OCD, perhaps especially OCD related to tic or movement disorders (Orefici et al., 2016). An ongoing European longitudinal observational multicenter study is investigating the association of environmental (e.g. infectious agents) factors with the onset and course of tics and/or OC symptoms through the prospective observation of at-risk individuals (Schrag et al., 2018). Finally, a recent genomewide association study found genetic correlations between immune-related disorders and several psychiatric disorders, including OCD (Tylee et al., 2018).

Although some studies demonstrated that OCD symptoms have improved with plasma exchange, intravenous immunoglobulin and antibiotic prophylaxis (e.g. Snider et al., 2005), the use of antibiotics and immunoglobulins for early and acute onset OCD patients remains controversial (Burchi and Pallanti, 2018; Williams et al., 2016).Additional evidence hints at a potential therapeutic role for antiinflammatory agents (Spartz et al., 2017). Interestingly, SSRIs (a first line OCD treatment) have been shown to exert several immunological effects, such as reduced lymphocyte proliferation, alteration of cytokine secretion and induction of apoptosis (Gobin et al., 2014).

Therefore, when treating a patient presenting with early onset OCRD, clinicians should consider an assessment of inflammatory and immunological aspects, such as infective history, OCD symptom-course, inflammatory markers, familial history of autoimmunity and the gut-microbiota. Early recognition of inflammatory and immunological factors in early and acute onset OCD patients may represent a crucial 
starting point for appropriate intervention in this population and could potentially advance the field toward a putative etiological treatment of OCD.

\section{Monitoring and Early Prevention Via Remote Digital Assessment}

The extensive use of smartphones and vast amount of information they contain, has positioned cellular devices and technology as a rich database for behavioural and social activities (World Health Organization Report (2011)). Harnessing smartphone technology into the clinical field has introduced new, real time, data sources that hold promise in characterizing clinical functioning (The National Institute of Mental Health (2017)). Characterizing clinical populations based on such data sources, known as digital phenotyping, is a new way of identifying individuals at risk, appropriately deploying interventions, and assessing their efficacy (Faurholt-Jepsen et al ., 2017).

Clinical disorders characterized by heightened compulsivity (e.g. OCD , body dysmorphic disorder, gambling disorder, restricting anorexia nervosa), represent disorders for which the human-device interface can putatively represent a significant area of observed symptomatology. Applications like 'Instagram' have issued health support platforms for their users, in response to acknowledging that mental health symptoms are linked with the use of its platform. PUl-related symptoms are prevalent in specific age groups of individuals with OCD (loannidis et al., 2018). While the concept of PUI is still under debate, and the direction of causation of the observed correlations is still contentious, there is anecdotal evidence that the online platforms facilitate a 'millieu' in which OCD symptoms flourish (Mazmanian et al., 2017). 
Digital monitoring is most relevant in groups for whom there is a high risk of delayed or missed diagnosis, where health services compliance is low and symptoms are often concealed, such as adolescents and young adults. Therefore, there is an argument for the use of digital phenotyping, created using an anonymous monitoring app, downloaded by those in high risk groups. The resulting data would enrich clinical monitoring with an objective and continuous data source. Therefore, data mining methods are highly relevant for the early detection and diagnoses of OCRD, where compulsions may be performed using the human-device interface (online checking, taking photos, list making etc.) and can provide a unique digital signature, which can be statistically characterized. This may open a wide array of novel screening methods and digital instruments, which can boost early detection of OCRDs. Although self-report of OCRD symptoms has a generally acceptable reliability, such methods, have the propensity to source high dimensional $24 \mathrm{~h}$ longitudinal data and enable the detection of covert symptoms which are otherwise hard to subjectively or objectively monitor, due to their nature (e.g. complex diurnal variation). Thus, several clinical situations characterizing OCRD could be better understood, and possibly prevented, by employing a digital personalized model capable of predicting when certain deviations from a patient's usual behavior may lead, with high probability, to his or her health deterioration, or indicate that a deterioration has already occurred.

During this informatics age, it is highly important that personal information is handled sensitively and the right to private life is respected in the digital space. Therefore, it is essential to highlight that a collection of personalized data of such nature, should be managed through rigorous processes and via secure mediums and databases, for which participants have given explicit consent. Researchers and clinicians setting up such processes would undertake this endeavour with grave ethical sincerity. Data 
collection of such magnitude and sensitivity would be acceptable, if it was completely anonymous. As such, techniques can be implemented by which devices could allow the sourcing of passive data sources (communication and diurnal variation patterns, social media and internet use, gyroscope movement, app usage, location information, word use and keyboard use), along with anonymous active data sources (voice prosody, facial and eye coding, linguistic analysis, remote survey). Computational approaches in machine learning (e.g. data mining) and artificial intelligence may then be used to derive clinical characterization and prediction based on these sources of big data, creating clinically valid screening and monitoring algorithms, which could be applied for early detection and intervention in high risk populations.

\section{Toward Primary, Secondary and Tertiary Prevention?}

In considering the development of early intervention strategies, it can be useful to conceptualise the 'prevention' of OCD and OCRDs in terms of primary, secondary and tertiary prevention. Primary prevention involves the prevention of the development of OC symptoms. Secondary prevention refers to the early identification and treatment of individuals who develop OC symptoms to prevent progression to OCRDs. Evidence shows that patients continue to improve over time and those who stay longer under treatment tend to benefit more from it. Therefore, the earlier the patient starts getting treated, the more likely he/she will stay under treatment long enough to improve (Costa et al., 2017, Jakubovski et al., 2012, Diniz et al., 2011). Tertiary prevention aims to reduce the impact of the disorder and the level of disability once individuals have been diagnosed. However, the literature in relation to the prevention of OCRDs is sparse. 
A combination of genetic and environmental factors appear to be relevant to the aetiology of OCD, e.g. the observation that hoarding symptoms and contamination/cleaning symptoms are more likely to also be present in first-degree relatives (Brakoulias et al., 2016b, Zilhão et al., 2018). These factors are thought to interact to precipitate OCD in individuals with subthreshold symptoms. Thus the primary prevention of OCD could involve strategies to prevent the genetic expression of OCD or modifying environmental factors that might contribute to the expression of OCD. As genetic strategies have not yet advanced to a stage of being used therapeutically (see above), we must currently look towards environmental factors. For $80 \%$ of people with OCD, their symptoms begins in childhood (Goodman et al., 1995), with the first peak of onset being reported around 11 years of age (Taylor, 2011). Early-life factors, including physical abuse, negative emotionality, perinatal insults, poor motor-development and personality or conduct problems have been reported to predict the incidence of OCD (Grisham et al., 2011). Hence childhood environmental factors are a target area of investigation.

Psychoeducation and the reduction of family accommodation, i.e. the act of parents, siblings or partners accommodating to the high-risk individual's requests to comply with their compulsions, are promising areas for primary prevention, but have only been evaluated as secondary preventative measures with some evidence that CBT-based family intervention programmes improve treatment outcomes (Merlo et al., 2009). Thus, currently the impact of such programmes on the long term prognosis is unknown.

, The advantages of anticipating treatment initiation through early intervention, so that patients can benefit from long-term improvement with treatment maintenance, requires evaluation in long term studies. Nevertheless, it can be postulated that early intervention in childhood provides an opportunity to reduce symptoms and their impact on a child's ability to meet developmental milestones (Freeman et 
al., 2007).The hypothesis that some OCRDs may be precipitated by neuro-immunological reactions has spurred several treatment studies. Although the generalisability of immune modulating interventions remains unclear, if OC symptoms are detected early, such treatments could be viewed as secondary prevention or early intervention. Biomarkers that might predict who will respond to these often costly and limited treatments are also required.

Tertiary prevention has been limited by an inadequate number of trained clinicians to deliver evidence based treatments such as exposure and response prevention therapy (Brakoulias et al., 2016a). Tertiary prevention would also aim to reduce the significant comorbidity associated with OCD with approximately 75\% having a co-occurring other anxiety disorder (Brakoulias et al., 2011) and higher rates of ADHD, tic disorders, major depression (Hasler et al., 2007) and suicide (Alonso et al., 2010, Maina et al., 2007, Kamath et al., 2007). Indeed, OCD was one of the most important predictors of lifetime comorbidity in the World Mental Health Surveys and, as an early-onset disorder, represents an important marker of youth at high risk for progression to later disorders (Kessler et al., 2011). The wider dissemination of clinical practice guidelines promoting evidence-based treatments (e.g. National Institute for Health and Clinical Excellence 2006, Menchon et al., 2017) could be seen to assist tertiary prevention.

\section{Early intervention in low and middle income countries}

The importance of developing early intervention programs for mental health problems in low and middle and low-income countries (LMIC) is obvious. First and foremost, as the majority of the world population resides in LMIC, most individuals with or "at risk" for OCRDs live in these regions. Secondly, 
most of the research on both OCRDs and early intervention has been performed in high-income countries (HIC), thus excluding individuals with different ethnic and sociocultural backgrounds (Durkin et al., 2015). It is therefore unclear how data from HIC samples apply to subjects from LMIC. Finally, the amount of resources that can be dedicated to early intervention for mental health problems (including OCRDs) is both lower than those from HIC and more likely to be affected by problems such as political instability, economic crisis, or even war, among others (Parra-Cardona et al., 2018). However, the concept of LMIC is also heterogeneous. For instance, countries with stronger economies, such as Brazil, Russia, India, China, and South Africa (collectively known as the BRICS) were able to establish an early intervention program for psychosis and to perform relevant research in OCRDs (e.g. Reddy et al., 2010). It is natural for them, therefore, to turn their attention to early intervention for OCRDs.

There is now evidence from studies performed in some LMIC that DUI in OCD is similar to those in other parts of the world (Poyraz et al., 2015). For instance, a recent Brazilian study found that the mean DUI, calculated as the age at which patients were first seen by a mental health professional minus the age at onset of OCD, was almost eight years (Vigne et al., 2018). However, DUI in OCD may be shortened by other targeted enterprises. In 2003, seven Brazilian universities established The Brazilian Research Consortium for Obsessive-Compulsive Spectrum Disorders to strengthen and develop research on OCRDs across the country (Miguel et al., 2008).This initiative was made possible by significant investments of the Brazilian research funding agencies, which allowed training in OCRDs' assessments across different centres, and also by the structure of the Brazilian health system itself, which is universal, comprehensive, decentralised, and free of charge in terms of service provision. These initiatives helped to establish Brazil as one of the research hubs in OCRDs and also to leverage assessment and treatment of OCRD across the country. 
In this specific context, attempts to shorten DUI in OCRDs should probably involve greater contact between local mental health specialists and family physicians, one of the tenets of the Brazilian mental health system (Fagundes Junioret al., 2016). Nevertheless, if we consider the DUI as the delay between the awareness of the discomfort or interference in functioning caused by OCD symptoms - instead of OCD symptoms onset - and the initiation of OCD-specific treatment, the mean DUI is still substantially high (Miguel et al., 2008). Therefore, even in the context of universal access to public health services in LMIC such as Brazil, there is a significant delay to OCD-specific treatment initiation explained by factors that go beyond treatment availability.

\section{Integration}

OCD has a profound impact on the quality of life of the subject and involves a significant burden on the individual, the family and society. The consequences of OCD may be increased by the frequently associated comorbidities, such as depression or anxiety disorders. Individuals suffering with OCD that has either not been detected or not properly treated are likely to experience these consequences. The recognition that $O C D$ occurs within an expanded diagnostic class of OCRDs, with a combined prevalence estimated at 9.1\% (OCD + OCD related disease prevalence) (Carmi et al., 2019), implies that OCD and OCRD are affecting roughly one out of 11 of the general population.

OCD frequently emerges in childhood and adolescence, and through the burden (which evolves) of the time and energy spent on the OCD, has the potential to (and often does) interfere with the achievement of social and occupational milestones. These secondary phenomena (lacking social occupational and 
interpersonal skills) add another degree of difficulty and resistance to treatment that could have been averted, had treatment started earlier. The same is true for secondary depression, which is common and very frequently presents another hurdle on the road to recovery

The issue of DUI in OCD is different from other severe brain disorders, as it is quite likely that for many individuals there is the possibility to disguise the symptoms from family and friends for some considerable time. The ego - dystonic features (symptoms accepted as integral to the individual's values and goals) and poor insight (unawareness that the obsession and / or compulsion is excessive or unreasonable) frequently seen in OCD may also deter individuals from coming forward. Moreover, as the symptoms are frequently territorial and narrowly focused (as opposed to depression, psychosis etc.), OCD is more likely to escalate under the "clinical radar" and consequently exerts an even bigger (unwanted) effect, not only on quality of life but also on psycho-social functioning.

Due to the specific characteristics of OCD (ego-dystonic and territoriality) on the one hand and the tendency of the disorder to get worse over time (as opposed to the usually episodic course of MDD for example), OCD and OCRDs are conditions for which early detection is both challenging and critical. Another relevant point relates to the known "toxic effects" of the illness; longer duration is not only associated with increase in severity and burden, but also interfaces with other domains ranging from occupation to social life, parenting and personal relationship. As the impact on the quality of life worsens with the passage of time, the relevance and importance of early detection and intervention for these disorders appears obvious. 
We therefore recommend adoption and validation of a staging model for OCD, linked to primary, secondary, tertiary prevention, focussing on addressing environmental and biological etiological targets. As we do not as yet have evidence that, by addressing modifiable environmental risk factors such as parental rearing practices, the primary prevention of full-blown OCD in individuals thought to be at risk is possible, early intervention is likely to be of greater importance for clinicians and health services. This model has scope for application at a global level, including among LMIC. Moreover, recent advances in information technology have the capacity to transform the way we approach early intervention and change the landscape in this regard.

The emphasis on early detection rests upon the known clinical and cost effectiveness of currently available interventions (SRIs, ERP, family interventions)( National Institute for Health and Clinical Excellence 2006). By applying these treatments early, there is a real possibility of altering (positively) the trajectory of OCD and OCRD, to enable patients to free themselves from the prison of their symptoms and access the opportunity to fulfill their potential. This component i.e. the availability of effective therapeutic tools, gives early intervention for OCD clinical weight. "Had we done it, it would really have had significant clinical impact".

Thus, early detection and intervention strategies could be expected to prevent chronic evolution, are likely to be cost-effective and to improve the quality of life and reduce the overall burden of illness. Achievable objectives include reliable identification of 'at risk' and established cases of OCD e.g. based on family history, phenotype and significant life events such as pregnancy and childbirth, alongside timely diagnosis and improved access to clinicians and services capable of providing targeted interventions, with the explicit aim of reducing the DUI and consequently the treatment gap and its 
damaging effects on mental wellbeing. As OCD is an illness with its onset in childhood and early to middle adulthood, there are strong arguments for targeting such interventions in child and adolescent mental health services, services covering the 'transitional' phase between childhood and adulthood and maternity services.

As many at risk individuals will not turn out to develop $O C D$, and we do not as yet have reliable outcome predictors to determine who will, it is proper to consider the potential harms of early intervention in the prodromal stages. For example, undue emphasis may be placed on dysfunctional behaviours that spontaneously remit. These 'false positive' findings may cause unnecessary anxiety or distress, especially for parents of at risk children, and may even lead to unnecessary interventions in some cases. These harms are not specific to OCD, relating to early interventions for many other conditions associated with a disease burden, and need to be balanced against known harms related to missing the diagnosis. Based on evidence presented in this review, we believe that careful monitoring of ultra-high risk cases of OCD is reasonable, not only because of the increased risk of developing $O C D$, but also because cases with a family history of OCD may have a six times lower response to CBT (Garcia et al., 2010) and so need to be identified early and treated appropriately. We would therefore argue that an early intervention model for OCD, with the level of intervention matched to the stage of illness, aligns with the precautionary principle guiding public health organizations' recommendations and actions, requiring that "... scientific uncertainty should not be used as a reason to postpone preventive measures" (World Health Organization, 2018).

\section{Limitations}


This consensus statement is not a systematic review. Systematic reviews come with their own weaknesses e.g. bias driven by the selection of search strategy chosen by the authors, and therefore do not represent a flawless process. We believe a narrative review is best suited for the purpose of such newly explored ground. We acknowledge there is as yet little or no prospective evidence that early intervention will actually result in better outcomes. Nevertheless, the consensus opinion of this global group of experts, derived from this narrative review, is that early intervention based on validated staging models, yet to be fully defined, represents the way forward. 


\section{References}

Aguglia, A., Signorelli, M.S., Albert, U., Maina, G., 2018.The Impact of General Medical Conditions in Obsessive-Compulsive Disorder. Psychiatry Investig. 15(3), 246-253.

Albert, U., Bogetto, F., Maina, G., Saracco, P., Brunatto, C., Mataix-Cols, D., 2010. Family accommodation in obsessive-compulsive disorder: Relation to symptom dimensions, clinical and family characteristics. Psychiatry Res.179(2),204-11.

Albert, U., Baffa, A., Maina, G., 2017. Family accommodation in adult obsessive-compulsive disorder: clinical perspectives. Psychol Res Behav Manag. 10, 293-304.

Albert, U., Barbaro, F., Bramante, S., Rosso, G., De Ronchi, D., Maina G., 2018a. Duration of untreated illness and response to treatments in obsessive-compulsive disorder. Article in submission November 2018

Albert, U., Barbaro, F., Bramante, S., Maina, G., 2018b. Duration of untreated illness, dynamic adherence and response to treatment in OCD. Eur Psychiatry.Poster abstract 48S, S54.

Alonso, P., Segalas, C., Real, E., Pertusa, A., Labad, J., Jimenez-Murcia, S., Jaurrieta, N., Bueno, B., Vallejo, J., Menchón, J. M., 2010. Suicide in patients treated for obsessive-compulsive disorder: a prospective follow-up study. Journal of Affective Disorders 124, 300-308.

Altamura, A.C. , Buoli, M. , Albano, A., Dell'Osso B., 2010. Age at onset and latency to treatment (duration of untreated illness) in patients with mood and anxiety disorders: a naturalistic study. Int Clin Psychopharmacol . 25, 172- 179.

American Psychiatric Publishing, 2013, Diagnostic and Statistical Manual of Mental Disorders, Fifth Edition, American psychiatric Publishing, Washington, DC. 
Angst, J., Gamma, A., Endrass, J., Hantouche, E., Goodwin, R., Ajdacic, V., Eich, D., Rössler, W., 2005. Obsessive-compulsive syndromes and disorders: significance of comorbidity with bipolar and anxiety syndromes. Eur Arch Psychiatry Clin Neurosci. 255(1), 65-7

Anderson, K.K., Voineskos, A., Mulsant, B.H., George, T.P., Mckenzie, K.J., 2014.The role of untreated psychosis in neurodegeneration: a review of hypothesized mechanisms of neurotoxicity in first-episode psychosis. Can J Psychiatry. 59(10), 513-7.

Atmaca, M., Yildirim, H., Ozdemir, H., Ozler, S., Kara, B., Ozler, Z., Kanmaz, E., Mermi, O., Tezcan, E. 2008. Hippocampus and amygdalar volumes in patients with refractory obsessive-compulsive disorder. Prog Neuropsychopharmacol Biol Psychiatry. 32(5),1283-6.

Attwells, S., Setiawan, E., Wilson, A.A., Rusjan, P.M., Mizrahi, R., Miler, L., Xu, C., Richter, M.A. Kahn, A., Kish, S.J., Houle, S., Ravindran, L., Meyer J.H., 2017. Inflammation in the Neurocircuitry of ObsessiveCompulsive Disorder. JAMA Psychiatry 74(8), 833-840.

Bebbington, P.E ., 1998. Epidemiology of obsessive-compulsive disorder. Brit J Psychiatry, Suppl 35, 2- 6.

Benatti, B., Camuri, G., Dell'Osso, B., Cremaschi, L., Sembira, E., Palazzo, C., Oldani, L., Dobrea, C., Arici, C., Primavera, D., Carpiniello, B., Castellano, F., Carrà, G., Clerici, M., Baldwin, D.S., Altamura, A.C., 2016. Which factors influence onset and latency to treatment in generalized anxiety disorder, panic disorder, and obsessive-compulsive disorder? Int Clin Psychopharmacol. 31(6), 347-52.

Berk, M., Post, R., Ratheesh, A., Gliddon, E., Singh, A., Vieta, E., Carvalho ,A.F., 2017. Staging in bipolar disorder: from theoretical framework to clinical utility. World Psychiatry, 16(3), 236-244. doi: 10.1002/wps.20441. 
Boedhoe, P.S.W., Schmaal, L., Abe, Y., Alonso, P., Ameis, S.H., Anticevic, A., Arnold, P.D., Batistuzzo, M.C,, Benedetti, F., Beucke, J.C,, Bollettini, I., Bose, A., Brem, S., Calvo, A., Calvo, R., Cheng, Y., Cho, K.I.K., Ciullo, V., Dallaspezia, S., Denys, D., Feusner, J.D., Fitzgerald, K.D., Fouche, J.P., Fridgeirsson, E.A., Gruner, P., Hanna, G.L., Hibar, D.P., Hoexter, M.Q., Hu, H., Huyser, C., Jahanshad, N., James, A., Kathmann, N., Kaufmann, C., Koch ,K., Kwon, J.S., Lazaro, L., Lochner, C., Marsh, R., Martínez-Zalacaín, I., Mataix-Cols, D., Menchón, J.M., Minuzzi, L., Morer, A., Nakamae, T., Nakao, T., Narayanaswamy, J.C., Nishida, S., Nurmi, E., O'Neill, J., Piacentini ,J., Piras, F., Reddy ,Y.C.J., Reess, T.J., Sakai, Y., Sato, J.R., Simpson, H.B., Soreni, N., Soriano-Mas, C., Spalletta, G., Stevens, M.C., Szeszko, P.R., Tolin, D.F., van Wingen, G.A., Venkatasubramanian, G., Walitza, S., Wang, Z., Yun, J.Y., Thompson, P.M., Stein, D.J., van den Heuvel, O.A.; ENIGMA OCD Working Group, 2018. Cortical Abnormalities Associated With Pediatric and Adult Obsessive-Compulsive Disorder: Findings From the ENIGMA Obsessive-Compulsive Disorder Working Group. Am J Psychiatry. 175(5), 453-462. doi: 10.1176/appi.ajp.2017.17050485.

Boedhoe, P.S.W., Schmaal, L., Abe, Y., Ameis, S.H., Arnold, P.D., Batistuzzo, M.C,, Benedetti, F., Beucke, J.C,, Bollettini, I., Bose, A., Brem, S., Calvo, A., Calvo, R., Cheng, Y., Cho, K.I.K., Dallaspezia, S., Denys, D., Fitzgerald,K.D., Fouche, J.P., Giménez, M., Gruner, P., Hanna, G.L., Hibar, D.P., Hoexter, M.Q., Hu, H., Huyser, C., Ikari, K., Jahanshad, N., Kathmann, N., Kaufmann, C., Koch ,K., Kwon, J.S., Lazaro, L., Lochner, C., Marsh, R., Martínez-Zalacaín, I., Mataix-Cols, D., Menchón, J.M., Minuzzi, L., Nakamae, T., Nakao, T., Narayanaswamy, J.C., Piras, F., Pittenger, C., Reddy, Y.C., Sato, J.R., Simpson, H.B., Soreni, N., SorianoMas, C., Spalletta, G., Stevens, M.C., Szeszko, P.R., Tolin, D.F., van Wingen, G.A.,Venkatasubramanian, G., Walitza, S., Wang, Z., Xu, J., Xu, X., Yun, J.Y., Zhao, Q., ENIGMA OCD Working Group, Thompson, P.M., Stein, D.J., van den Heuvel ,O.A., 2017. Distinct Subcortical Volume Alterations in Pediatric and Adult OCD: A Worldwide Meta- and Mega-Analysis. Am J Psychiatry, 174(1), 60-69. doi:

10.1176/appi.ajp.2016.16020201. 
Brakoulias, V., Starcevic, V., Belloch, A., Dell'osso, L., Ferrão, Y. A., Fontenelle, L. F., Lochner, C., Marazziti, D., Martin, A. \& Matsunaga, H., 2016a. International prescribing practices in obsessive-compulsive disorder (OCD). Hum Psychopharmacol. 31(4), 319-24. doi: 10.1002/hup.2541.

Brakoulias, V., Starcevic, V., Martin, A., Berle, D., Milicevic, D. \& Viswasam, K. 2016b. The familiality of specific symptoms of obsessive-compulsive disorder. Psychiatry research, 239, 315-319.

Brakoulias, V., Starcevic, V., Sammut, P., Berle, D., Milicevic, D., Moses, K. \& Hannan, A. 2011. Obsessivecompulsive spectrum disorders: a comorbidity and family history perspective. Australasian Psychiatry, 15.

Brakoulias, V., Perkes, I.E., Tsalamanios, E., 2018. A call for prevention and early intervention in obsessivecompulsive disorder. Early Interv Psychiatry. .12(4):572-577.

Burchi, E., Hollander, E. and Pallanti, S., 2018. From Treatment Response to Recovery - a Realistic Goal in OCD. International Journal of Neuropsychopharmacology, 21(11),1007-1013. doi: 10.1093/ijnp/pyy0792018.

Burchi, E., Pallanti, S., 2018. Antibiotics for PANDAS? Limited Evidence: Review and Putative Mechanisms of Action. Prim Care Companion CNS Disord, May 3, 20(3). pii: 17r02232. doi: 10.4088/PCC.17r02232.

Carmi, L., Fineberg ,N., Ben Arush, O., Zohar, J., 2019. Epidemiology of OCD, in: Geddes JR, Andreasen NC and Goodwin GM (Eds), New Oxford Textbook of Psychiatry 3edn. Oxford University Press, Oxford, UK. In press November 2018.

Chamberlain, S.R., Blackwell, A.D., Fineberg, N.A., Robbins, T.W., Sahakian, B.J., 2005. The neuropsychology of obsessive compulsive disorder: the importance of failures in cognitive and behavioural inhibition as candidate endophenotypic markers. Neurosci Biobehav Rev. 29(3), 399-419 
Chiarello, F., Spitoni, S., Hollander, E., Matucci Cerinic, M., Pallanti S., 2017. An expert opinion on PANDAS/PANS: highlights and controversies. Int J Psychiatry Clin Pract. 21(2), 91-98.

Coluccia, A., Fagiolini, A., Ferretti ,F., Pozza, A., Costoloni, G., Bolognesi ,S., Goracci, A., 2016. Adult obsessive-compulsive disorder and quality of life outcomes: A systematic review and meta-analysis. Asian J Psychiatr. 22, 41-52.

Costa, D.L.C., Diniz, J.B., Requena, G., Joaquim, M.A., Pittenger, C., Bloch, M.H., Miguel, E.C., Shavitt, R.G. 2017. Randomized, Double-Blind, Placebo-Controlled Trial of N-Acetylcysteine Augmentation for Treatment-Resistant Obsessive-Compulsive Disorder. J Clin Psychiatry. 78(7):e766-e773. doi: 10.4088/JCP.16m11101.

Dell'Osso, B., Buoli, M., Hollander, E., Altamura ,A.C., 2010. Duration of untreated illness as a predictor of treatment response and remission in obsessive-compulsive disorder. World J Biol Psychiatry, 11(1),59-65.

Dell'Osso, B., Altamura, A.C., 2010. Duration of untreated psychosis and duration of untreated illness: new vistas. CNS Spectrums, 15(4), 238-46.

Dell'osso, B., Benatti, B., Buoli, M., Altamura, A.C., Marazziti, D., Hollander, E., Fineberg, N., Stein, D.J., Pallanti, S., Nicolini, H., Ameringen, M.V., Lochner, C., Hranov , G., Karamustafalioglu, O., Hranov, L., Menchon, J.M., Zohar, J; on behalf of the ICOCS group, 2013a.The influence of age at onset and duration of illness on long-term outcome in patients with obsessive-compulsive disorder: A report from the International College of Obsessive Compulsive Spectrum Disorders (ICOCS). Eur Neuropsychopharmacol. 23(8), 865-71. doi: 10.1016/j.euroneuro.2013.05.004. Epub 2013 Jun 21.

Dell'Osso, B., Camuri, G., Benatti, B., Buoli, M., Altamura, A.C., 2013b. Differences in latency to first pharmacological treatment (duration of untreated illness) in anxiety disorders: a study on patients with 
panic disorder, generalized anxiety disorder and obsessive-compulsive disorder. Early intervention in psychiatry, 7(4), 374-80.

Dell'Osso, B., Glick, I.D., Baldwin, D.S., Altamura, A.C., 2013c. Can long-term outcomes be improved by shortening the duration of untreated illness in psychiatric disorders? A conceptual framework. Psychopathology,46(1),14-21.

Dell'Osso, B., Benatti ,B., Oldani, L., Spagnolin, G., Altamura, A.C., 2015. Differences in duration of untreated illness, duration, and severity of illness among clinical phenotypes of obsessive-compulsive disorder. CNS Spectrums,20(5), 474-8.

Dell'Osso, B., Benatti, B., Hollander, E., Fineberg, N., Stein, D.J., Lochner, C., Nicolin,i H., Lanzagorta, N., Palazzo, C., Altamura, A.C., Marazziti, D., Pallanti, S., Van Ameringen, M., Karamustafalioglu, O., Drummond, L.M., Hranov, L., Figee, M., Grant ,J.E., Zohar, J., Denys, D., Menchon, J.M., 2016 a. Childhood, adolescent and adult age at onset and related clinical correlates in obsessive-compulsive disorder: a report from the International College of Obsessive-Compulsive Spectrum Disorders (ICOCS). Int J Psychiatry Clin Pract. 19, 1-8. PMID:27433835

Dell'Osso, B., Oldani, L., Camuri, G., Benatti, B., Grancini, B., Arici, C., Cremasch , L., Palazzo, M., Spagnolin, G., Dobrea, C., Altamura, A.C., 2016b. Reduced duration of untreated illness over time in patients with schizophrenia spectrum, mood and anxiety disorders. Psychiatry Clin Neurosci.70(5),20210.

Dell'Osso, B., Benatt,i B., Hollander, E., Altamura, A.C., 2017. Clinical features associated with increased severity of illness in tertiary clinic referred patients with obsessive compulsive disorder. Int J Psychiatry Clin Pract. 21(2),131-136. 
de la Fuente-Tomas, L., Sánchez-Autet, M., García-Álvarez L., González-Blanco, L., Velasco, Á., Sáiz Martínez , P.A., Garcia-Portilla, M.P., Bobes, J., 2018. Clinical staging in severe mental disorders; bipolar disorder, depression and schizophrenia. Rev Psiquiatr Salud Ment. Oct 9. pii: S1888-9891(18)30073-9. doi: 10.1016/j.rpsm.2018.08.002. [Epub ahead of print] English

De Luca, V. , Gershenzon, V. , Burroughs, E., Javaid, N., Richter, M.A ., 2011. Age at onset in Canadian OCD patients: mixture analysis and systematic comparison with other studies . J Affect Dis. 133, 300304.

Diniz, J.B., Shavitt, R.G., Fossaluza, V., Koran, L., Pereira, C.A., Miguel, .EC., 2011. A double-blind, randomized, controlled trial of fluoxetine plus quetiapine or clomipramine versus fluoxetine plus placebo for obsessive-compulsive disorder. J Clin Psychopharmacol. 31(6):763-8. doi: 10.1097/JCP.0b013e3182367aee.

Drummond, L.M., 1993. The treatment of severe, chronic, resistant obsessive-compulsive disorder. An evaluation of an in-patient programme using behavioural psychotherapy in combination with other treatments. Br J Psychiatry, 163, 223-9

Dupont, R.L., Rice, D.P., Shiraki, S., Rowland ,C.R., 1995. Economic costs of obsessive-compulsive disorder. Med Interface, 8, 102-109.

Durkin, M.S., Elsabbagh, M., Barbaro, J., Gladstone, M., Happe, F., Hoekstra, R.A., Lee, L.C., Rattazzi, A., Stapel-Wax, J., Stone, W.L., Tager-Flusberg, H., Thurm, A., Tomlinson, M., Shih, A., 2015. Autism screening and diagnosis in low resource settings: Challenges and opportunities to enhance research and services worldwide. Autism research: official journal of the International Society for Autism Research, $8(5), 473-476$. 
Eaton, W.W., Martins, S.S., Nestadt, G., Bienvenu, O.J., Clarke, D., Alexandre, P., 2008. The burden of mental disorders. Epidemiol Rev. 30, 1-14.

Edwards, J., McGorry, P., 2002. Multi-component early intervention - models of good practice. In: Edwards J, McGorry PD editor(s). Implementing Early Intervention in Psychosis. London: Martin Dunitz, 63-84.

Eisen, J.L., Goodman, W.K., Keller, M.B., Warshaw, M.G., DeMarco, L.M., Luce, D.D., Rasmussen, S.A., 2013. Patterns of remission and relapse in obsessive-compulsive disorder: a 2-year prospective study. J Clin Psychiatry, 74(3), 233-239. doi: 10.4088/JCP.12m07657

Fagundes Junior, H.M., Desviat, M., Silva, P.R., 2016. Psychiatric Reform in Rio de Janeiro: the current situation and future perspectives. Ciencia \& saude coletiva,21(5),1449-1460.

Fatori, D., de Bragança Pereira, C.A., Asbahr, F.R., Requena, G., Alvarenga, P.G., de Mathis, M.A., Rohde, L.A., Leckman, J.F., March, J.S., Polanczyk, G.V., Miguel, E.C., Shavitt, R.G., 2018. Adaptive treatment strategies for children and adolescents with Obsessive-Compulsive Disorder: A sequential multiple assignment randomized trial.J Anxiety Disord. 58, 42-50. doi: 10.1016/j.janxdis.2018.07.002.

Faurholt-Jepsen, M., Bauer, M., Kessing, L.V., 2018. Smartphone-based objective monitoring in bipolar disorder: status and considerations. Int J Bipolar Disord. 6(1), 6. doi: 10.1186/s40345-017-0110-8.

Fineberg, N.A., Hengartner, M.P., Bergbaum, C.E., Gale, T., Gamma, A., Ajdacic-Gross, V., Rössler, W., Angst, J., 2013a. A Prospective Population-Based Cohort Study Of The Prevalence, Incidence And Impact Of Obsessive-Compulsive Symptomatology. Int J Psychiatry Clin Pract. 17(3), 170-8. doi:

10.3109/13651501.2012.755206.

Fineberg, N.A., Hengartner, M.P., Bergbaum, C.E., Gale, T., Rössler, W., Angst, J., 2013b. Lifetime comorbidity of obsessive-compulsive disorder and sub-threshold obsessive-compulsive symptomatology 
in the community: impact, prevalence, socio-demographic and clinical characteristics. Int J Psychiatry Clin Pract. 17(3),188-96. doi: 10.3109/13651501.2013.777745.

Fineberg, N.A., Hengartner, M.P., Bergbaum, C.E., Gale, T., Rössler, W., Angst, J., 2013c. Remission of obsessive-compulsive disorders and syndromes; evidence from a prospective community cohort study over thirty years. Int J Psychiatry Clin Pract. 17(3), 179-87. doi: 10.3109/13651501.2013.777744.

Fineberg, N.A., Reghunandanan ,S., Simpson, H.B., Phillips, K.A., Richter, M.A., Matthews, K., Stein, D.J., Sareen, J., Brown, A., Sookman, D., 2015. Accreditation Task Force of The Canadian Institute for Obsessive Compulsive Disorders. Obsessive-compulsive disorder (OCD): Practical strategies for pharmacological and somatic treatment in adults. Psychiatry Res. 227(1),114-25. doi: 10.1016/j.psychres.2014.12.003.

Fineberg, N.A., Baldwin, D.S., Drummond, L.M., Wyatt, S., Hanson, J., Gopi, S., Kaur, S., Reid ,J., Marwah, V., Sachdev, R.A., Pampaloni ,I., Shahper, S., Varlakova, Y., Mpavaenda, D., Manson, C., O'Leary, C., Irvine, K., Monji-Patel, D., Shodunke, A., Dyer, T., Dymond ,A., Barton, G., Wellsted, D., 2018. Optimal treatment for obsessive compulsive disorder: a randomized controlled feasibility study of the clinicaleffectiveness and cost-effectiveness of cognitive-behavioural therapy, selective serotonin reuptake inhibitors and their combination in the management of obsessive compulsive disorder. Int Clin Psychopharmacol. 33(6), 334-348. doi: 10.1097/YIC.0000000000000237.

Frankovich, J., Swedo, S., Murphy, T., Dale, R.C., Agalliu, D., Williams, K., Daines, M., Hornig, M., Chugani, H., Sanger, T., Muscal, E., Pasternack, M., Cooperstock, M., Gans, H., Zhang, Y., Cunningham, M., Bernstein, G., Bromberg ,R., Willett, T., Brown, K., Farhadian ,B., Chang, K., Geller ,D., Hernandez, J., Sherr, J., Shaw, R., Latimer, E., Leckman, J., Thienemann, M., 2017. PANS/PANDAS Consortium. Clinical Management of Pediatric Acute-Onset Neuropsychiatric Syndrome: Part II-Use of Immunomodulatory Therapies. Journal of Child and Adolescent Psychopharmacology, 27(7), 574-593. 
Freeman, J. B., Choate-Summers, M. L., Moore, P. S., Garcia, A. M., Sapyta, J. J., Leonard, H. L. \& Franklin, M. E. 2007. Cognitive behavioral treatment for young children with obsessive-compulsive disorder. Biological Psychiatry, 61, 337-343.

Fullana, M.A., Mataix-Cols, D. , Caspi, A., Harrington, H., Grisham, J.R. , Moffi tt, T.E., Poulton, R ., 2009. Obsessions and compulsions in the community: prevalence, interference, help-seeking, developmental stability, and co-occurring psychiatric conditions . Am J Psychiatry, 166, 329- 336.

Fullana, M.A. , Vilagut, G. , Rojas-Farreras, S. , Mataix-Cols, D., de Graaf ,R. , Demyttenaere, K., 2010. Obsessive-compulsive symptom dimensions in the general population: results from an epidemiological study in six European countries. J Aff ect Dis. 124, 291- 299.

Garcia, A.M., Sapyta J.J., Moore, P.S., Freeman, J.B., Franklin, M.E., March, J.S., Foa, E.B., 2010. Predictors and moderators of treatment outcome in the Pediatric Obsessive Compulsive Treatment Study (POTS I). J Am Acad Child Adolesc Psychiatry, 49(10),1024-1033

Geller, D., Biederman, J., Faraone, S.V., Frazier, J., Coffey, B., Kim, G., Bellordre, C.A., 2000. Clinical correlates of obsessive compulsive disorder in children and adolescents referred to specialized and nonspecialized clinical settings. Depress Anxiety, 11, 163-68. doi: 10.1002/1520-6394(2000)11:4<163::AIDDA3>3.0.CO;2-3.

Geller, D., Biederman, J., Faraone, S.V., Agranat, A., Cradock, K., Hagermoser, L., Kim, G., Frazier,J., Coffey, B.J., 2001a. Developmental aspects of obsessive compulsive disorder: Findings in children, adolescents, and adults. J Nerv Ment Dis. 189, 471-77. doi: 0022-3018/01/1897-471.

Geller, D., Biederman, J., Faraone, S.V., Bellordre, C.A., Kim, G.S., Hagermoser, L., Cradock, K., Frazier, J., Coffey, B.J., 2001b. Disentangling chronological age from age of onset in children and adolescents with 
obsessive-compulsive disorder. Int J Neuropsychopharmacol. 4, 169-78. doi:

$10.1017 / \mathrm{S} 1461145701002395$.

Geller, D.A., Biederman, J., Stewart,S.E., Mullin, B., Martin, A., Spencer, T., Faraone, S.V., 2003. Which SSRI? A meta-analysis of pharmacotherapy trials in pediatric obsessive-compulsive disorder. Am J Psychiatry, 160, 1919-28. doi: 10.1176/appi.ajp.160.11.1919.

Geller, D., Petty, C., Vivas, F., Johnson, J., Pauls, D., Biederman J., 2007. Examining the relationship between obsessive-compulsive disorder and attention-deficit/hyperactivity disorder in children and adolescents: A familial risk analysis. Biol Psychiatry,61, 316-21. doi: 10.1016/j.biopsych.2006.03.083.

Geller, D.A., Wieland, N., Carey, K., Vivas, F., Petty, C.R., Johnson, J., Reichert, E., Pauls, D., Biederman, J., 2008. Perinatal factors affecting expression of obsessive compulsive disorder in children and adolescents. J Child Adolesc Psychopharmacol. 18, 373-79. doi: 10.1089/cap.2007.0112.

Geller, D.A., Abramovitch, A., Mittelman, A., Stark, A., Ramsey, K., Cooperman, A., Baer, L., Stewart, S.E., 2017. Neurocognitive Function in Pediatric Obsessive-Compulsive Disorder. World Journal of Biological Psychiatry, 16, 1-26. doi: 10.1080/15622975.2017.1282173.

Glazier, K., Calixte, R.M., Rothschild, R., Pinto, A., 2013. High rates of OCD symptom misidentification by mental health professionals. Ann Clin Psychiatry,25(3), 201-9.

Gnanave,I S., Sharan, P., Khandelwal, S., Sharma, U., Jagannathan, N.R., 2014. Neurochemicals measured by (1)H-MR spectroscopy: putative vulnerability biomarkers for obsessive compulsive disorder. MAGMA. 27(5), 407-17.

Gobin, V., Van Steendam, K., Denys, D., Deforce, D., 2014. Selective serotonin reuptake inhibitors as a novel class of immunosuppressants. Int Immunopharmacol. 20(1), 148-56. 
Goodman, W., Rasmussen, S. , Leckman, J. F., 1995. A family study of obsessive-compulsive disorder. Am J Psychiatry, 152, 76-84.

Grant, J.E. , Mancebo, M.C. , Pinto, A. , Williams, K.A. , Eisen, J.L. , Rasmussen, S.A ., 2007 . Late-onset obsessive compulsive disorder: clinical characteristics and psychiatric comorbidity . Psychiatry Res. 152 $: 21-27$

Grisham, J.R. , Fullana, M.A., Mataix-Cols, D. , Moffi tt, T.E., Caspi, A., Poulton, R., 2011 . Risk factors prospectively associated with adult obsessive compulsive symptom dimensions and obsessivecompulsive disorder. Psych Med, 15, 1- 12.

Grünblatt, E., Oneda, B., Ekici, A.B., Ball, J., Geissler, J., Uebe, S., Romanos, M., Rauch, A., Walitza, S., 2017. High resolution chromosomal microarray analysis in paediatric obsessive-compulsive disorder. BMC Med Genomics,10(1), 68. doi: 10.1186/s12920-017-0299-5.

Grünblatt, E., Marinova, Z,, Roth, A., Gardini, E., Ball, J., Geissler, J., Wojdacz, TK., Romanos M., Walitza S., 2018. Combining genetic and epigenetic parameters of the serotonin transporter gene in obsessivecompulsive disorder. J Psychiatr Res. 96, 209-217.

Heyman, I. , Fombonne, E. , Simmons, H. , Ford, T. , Meltzer, H ., Goodman ., 2001. Prevalence of obsessive-compulsive disorder in the British nationwide survey of child mental health. Brit J Psychiatry, $179,324-329$.

Hirschtritt, M.E., Bloch, M.H., Mathews, C.A., 2017. Obsessive-Compulsive Disorder: Advances in Diagnosis and Treatment. JAMA, 317(13),1358-1367.

Højgaard, D. R., Hybel, K. A., Ivarsson, T., Skarphedinsson, G., Becker Nissen, J. B., Weidle, B., Melin, K., Torp, N.C., Valderhaug, R., Dahl, K., Mortensen, E.L., Compton, S., Jensen, S., Lenhard, F., Thomsen, P.H., Mortensen, E. L., 2017. One-year outcome for responders of cognitive-behavioral therapy for pediatric 
obsessive-compulsive disorder. Journal of the American Academy of Child \& Adolescent Psychiatry, 56(11), 940-947.

Hollander, E., Stein, D.J., Fineberg, N.A., Marteau, F., Legault, M., 2010. Quality of life outcomes in patients with obsessive-compulsive disorder: relationship to treatment response and symptom relapse. J Clin Psychiatry, 71, 784-792.

Hollander, E., Doernberg, E., Shavitt, R., Waterman, R.J., Soreni , N., Veltman ,D.J., Sahakian, B.J., Fineberg ,N.A., 2016. The cost and impact of compulsivity: A research perspective European Neuropsychopharmacology , 26 (5), $800-809$.

House, S.J., Tripathi, S.P., Knight, B.T., Morris, N., Newport, D.J., Stowe, Z.N., 2016. Obsessivecompulsive disorder in pregnancy and the postpartum period: course of illness and obstetrical outcome. Arch Womens Ment Health. 19(1), 3-10. doi: 10.1007/s00737-015-0542-z.

Ioannidis, K., Treder, M. S., Chamberlain, S. R., Kiraly, F., Redden, S. A., Stein, D. J., Lochner, C., Grant, J. E., 2018. Problematic internet use as an age-related multifaceted problem: Evidence from a two-site survey. Addictive Behaviors, 81, 157-166. http://doi.org/10.1016/J.ADDBEH.2018.02.017

Jakubovski, E., Diniz, J.B., Valerio, C., Fossaluza, V., Belotto-Silva, C., Gorenstein, C., Miguel, E., Shavitt, RG., 2013. Clinical predictors of long-term outcome in obsessive-compulsive disorder. Depress Anxiety. 30(8):763-72. doi: 10.1002/da.22013. Epub 2012 Oct 25. PubMed PMID: 23109056.

Kamath, P., Reddy, Y. \& Kandavel, T., 2007. Suicidal behavior in obsessive-compulsive disorder. Journal of Clinical Psychiatry, 68, 1741-1750.

Kamath, P., Reddy, Y.C., Kandavel, T., 2007. Suicidal behavior in obsessive-compulsive disorder. J Clin Psychiatry. 68(11), 1741-50 
Kantak, P.A., Bobrow, D.N., Nyby, J.G., 2014. Obsessive-compulsive like behaviors in house mice are attenuated by a probiotic (Lactobacillus rhamnosus GG). Behav Pharmacol. 25(1), 71-79.

Kessler, R.C, Berglund, P., Demler, O., Jin ,R., Merikangas, K.R ., Walters, E.E .,2005a. Lifetime prevalence and age-of-onset distributions of DSM-IV disorders in the National Comorbidity Survey Replication. Arch Gen Psychiatry, 62, 593-602.

Kessler, R.C., Chiu W.T., Demler, O., Merikangas, K.R ., Walters, E.E., 2005b. Prevalence, severity, and comorbidity of 12-month DSM-IV disorders in the National Comorbidity Survey Replication. Arch Gen Psychiatry, 62, 617-627.

Kessler, R.C., Ormel, J., Petukhova, M., McLaughlin, K.A., Green, J.G., Russo, L.J., Stein ,D.J., Zaslavsky, A.M., Aguilar-Gaxiola, S., Alonso, J., Andrade, L., Benjet, C., de Girolamo, G., de Graaf, R., Demyttenaere, K., Fayyad, J., Haro, J.M., Hu, C.Y., Karam, A., Lee, S., Lepine, J.P., Matchsinger, H., Mihaescu-Pintia, C., Posada-Villa, J., Sagar, R., Ustün, T.B., 2011. Development of lifetime comorbidity in the World Health Organization world mental health surveys. Arch Gen Psychiatry, 68(1), 90-100.

Kichuk, S.A., Torres, A.R., Fontenelle, L.F., Rosário, M.C., Shavitt, R.G., Miguel ,E.C., Pittenger, C., Bloch M.H., 2013. Symptom dimensions are associated with age of onset and clinical course of obsessivecompulsive disorder. Prog Neuropsychopharmacol Biol Psychiatry, 44, 233-9.

Knapp, M., Henderson, J., Patel, A., 2002. Costs of Obsessive-Compulsive Disorder: A Review, in: Maj M, Sartorius N, Okasha A, Zohar J (Eds.). Obsessive-Compulsive Disorder. Wiley, New York, NY, pp25399.

Kohn, R., Saxena, S., Levav, I., Saraceno, B., 2004. The treatment gap in mental health care. Bull World Health Organ. 82(11), 858-66. 
Labad, J. , Menchon, J.M., Alonso, P. , Segalas, C., Jimenez, S., Jaurrieta, N., Leckman, J.F., Vallejo, J., 2008. Gender differences in obsessive-compulsive symptom dimensions. Depress Anxiety, 25, 832-838.

Macy, A.S., Theo, J.N., Kaufmann, S.C., Ghazzaoui ,R.B., Pawlowski, P.A., Fakhry, H.I., Cassmassi, B.J., IsHak, W.W., 2013. Quality of life in obsessive compulsive disorder. CNS Spectr. 18(1), 21-33.

Maina, G., Albert, U., Bogetto, F., 2001. Relapses after discontinuation of drug associated with increased resistance to treatment in obsessive-compulsive disorder. Int Clin Psychopharmacol. 16(1), 33-8.

Maina, G., Salvi, V., Tiezzi, M. N., Albert, U. \& Bogetto, F., 2007. Is OCD at risk for suicide? A case-control study. Clinical Neuropsychiatry: Journal of Treatment Evaluation, 4, 117-121.

Mancebo, M.C., Greenberg, B., Grant, J.E., Pinto, A., Eisen, J.L., Dyck, I., Rasmussen, S.A., 2008. Correlates of occupational disability in a clinical sample of obsessive-compulsive disorder. Compr Psychiatry, 49, 43-50.

Mancebo, M.C., Boisseau, C.L., Garnaat ,S.L., Eisen, J.L., Greenberg, B.D., Sibrava, N.J., Stout ,R.L., Rasmussen, S.A., 2014. Long-term course of pediatric obsessive-compulsive disorder: 3 years of prospective follow-up. Compr Psychiatry. 55(7), 1498-504. doi: 10.1016/j.comppsych.2014.04.010.

Mazmanian, M., Yates, J.,Orlikowski ,W., 2017. Published Online:30 Nov https://journals.aom.org/doi/abs/10.5465/ambpp.2006.27169074

Menchón, J.M., van Ameringen, M., Dell'Osso, B., Denys, D., Figee, M., Grant, J.E., Hollander, E., Marazziti, D., Nicolini, H., Pallanti, S., Ruck, C., Shavitt, R., Stein, D.J., Andersson, E., Bipeta, R., Cath, D.C., Drummond, L.M., Feusner, J., Geller, D.A., Hranov, G., Lochner, C., Matsunaga, H., McCabe, R.E., Mpavaenda, D., Nakamae, T., O'Kearney, R., Pasquini, M., Pérez Rivera, R., Poyurovsky, M., Real, E., do Rosário, M.C., Soreni ,N., Swinson, R.P., Vulink, N., Zohar, J., Fineberg, N., 2016. Standards of care for obsessive-compulsive disorder centres. Int J Psychiatry Clin Pract. 20(3), 204-8. 
Merlo, L. J., Lehmkuhl, H. D., Geffken, G. R., Storch, E. A., 2009. Decreased family accommodation associated with improved therapy outcome in pediatric obsessive-compulsive disorder. Journal of consulting and clinical psychology, 77, 355.

Micali, N., Heyman, I., Perez, M., Hilton, K., Nakatani, E., Turner, C., Mataix-Cols, D., 2010. Long-term outcomes of obsessive-compulsive disorder: follow-up of 142 children and adolescents. British Journal of Psychiatry. 197, 128-134.

Miguel, E.C., Ferrao, Y.A., Rosario, M.C., de Mathis, M.A., Rodrigues Torres, A., Fontenelle, L.F., Hounie, A.G., Shavitt,R.G., Cordioli, A.V., Gonzalez, C.H.,Petribú, C., Diniz,JB., Malavazzi, D.M., Torresan, R.C., Raffin, A.L., Meyer, E., Braga, D.T., Borcato, S., a Valério, C., Gropo, L.N.,da Silva Prado,H., Alliende Perin, E., Santos, S.L., Copque, H., Corrêa Borges, M., Prazeres Lopes, A., da Silva, E.D., The Brazilian Research Consortium on Obsessive-Compulsive Spectrum Disorders., 2008. The Brazilian Research Consortium on Obsessive-Compulsive Spectrum Disorders: recruitment, assessment instruments, methods for the development of multicenter collaborative studies and preliminary results. Revista brasileira de psiquiatria (Sao Paulo, Brazil : 1999), 30(3), 185-196.

Nair, A., Wong, Y.L., Barrow, F., Heyman, I., Clark, B., Krebs, G., 2015. Has the first-line management of paediatric OCD improved following the introduction of NICE guidelines? Arch Dis Child. 100(4), 416-7. doi: 10.1136/archdischild-2014-307900.

National Institute for Health and Clinical Excellence (NICE). 2006. Obsessive compulsive disorder: Core interventions in the treatment of obsessive compulsive disorder and body dysmorphic disorder. National Clinical Practice Guideline Number 31 (https://www.nice.org.uk/guidance/cg31/evidence/full-guidelinepdf-194883373) 
Nicholson, T. R., Ferdinando, S., Krishnaiah, R. B., Anhoury, S., Lennox, B. R., Mataix-Cols, D., Cleare, A., Veale, D. M., Drummond, L. M. \& Fineberg, N. A., 2012. Prevalence of anti-basal ganglia antibodies in adult obsessive-compulsive disorder: cross-sectional study. The British Journal of Psychiatry, 200, 381386.

Nissen, J.B., Thomsen, P.H., 2008. Clinicians' views on clinical examination and treatment of children and adolescents with obsessive-compulsive disorder (OCD). A Danish national survey study. Nord J Psychiatry, 62(4), 309-14. doi: 10.1080/08039480801984065.

Orefici, G., Cardona, F., Cox ,C.J., Cunningham, M.W. , 2016. Pediatric Autoimmune Neuropsychiatric Disorders Associated with Streptococcal Infections (PANDAS), in: Ferretti JJ, Stevens DL, Fischetti VA (Eds.). Streptococcus pyogenes : Basic Biology to Clinical Manifestations [Internet]. Oklahoma City (OK): University of Oklahoma Health Sciences Center.

Parra-Cardona, R., Leijten, P., Lachman, J.M., Mejía, A., Baumann, A.A., Amador Buenabad, N.G., Cluver, L., Doubt, J., Gardner, F., Hutchings, J., Ward, C.L., Wessels, I.M., Calam, R., Chavira, V., Domenech Rodríguez, M.M., 2018. Strengthening a Culture of Prevention in Low- and Middle-Income Countries: Balancing Scientific Expectations and Contextual Realities. Prev Sci. 2018 Jul 30. doi: 10.1007/s11121-0180935-0. [Epub ahead of print]PMID:30058025

Pearlman, D.M., Vora, H.S., Marquis, B.G., Najjar, S., Dudley, L.A., 2014. Anti-basal ganglia antibodies in primary obsessive-compulsive disorder: systematic review and meta-analysis. Br J Psychiatry, 205(1), 816.

Peris, T.S., Bergman, R.L., Langley, A., Chang, S., McCracken, J.T., Piacentini, J., 2008. Correlates of accommodation of pediatric obsessive compulsive disorder: parent, child, and family characteristics. J Am Acad Child Adolesc Psychiatry, 47(10), 1173-1181. 
Peris, T.S., Rozenman, M.S., Sugar, C.A., McCracken, J.T., Piacentini, J., 2017. Targeted Family Intervention for Complex Cases of Pediatric Obsessive-Compulsive Disorder: A Randomized Controlled Trial, 56(12), 1034-1042. doi: 10.1016/j.jaac.2017.10.008.

Pollitt J.,1957. Natural history of obsessional states. Brit Med J. 1, 194-198 .

Poyraz, C.A., Turan, Ş., Sağlam, N.G., Batun, G.Ç., Yassa, A., Duran, A., 2015. Factors associated with the duration of untreated illness among patients with obsessive compulsive disorder. Compr Psychiatry, 58, 88-93.

Quagliariello, A., Del Chierico, F., Russo, A., Reddel, S., Conte, G., Lopetuso, L.R., Ianiro, G., Dallapiccola, B., Cardona, F., Gasbarrini, A., Putignani, L., 2018. Gut Microbiota Profiling and Gut-Brain Crosstalk in Children Affected by Pediatric Acute-Onset Neuropsychiatric Syndrome and Pediatric Autoimmune Neuropsychiatric Disorders Associated With Streptococcal Infections. Front Microbiol. 9, 675.

Rao, N.P., Venkatasubramanian, G., Ravi, V., Kalmady, S., Cherian, A., Yc J.R., 2015. Plasma cytokine abnormalities in drug-naïve, comorbidity-free obsessive-compulsive disorder. Psychiatry Res. 229(3), 94952.

Rapoport, J.L., Inoff-Germain, G., Weissman, M.M., Greenwald, S., Narrow ,W.E., Jensen, P.S, Lahey, B.B., Canino, G., 2000. Childhood obsessive-compulsive disorder in the NIMH MECA study: Parent versus child identification of cases. J Anxiety Disord. 14, 535-48

Reddy, Y.C., Rao, N.P., Khanna, S., 2010. An overview of Indian research in obsessive compulsive disorder. Indian journal of psychiatry, 52(Suppl 1), S200-209.

Robins, L.N., Helzer, J.E., Weissman, M.M., Orvaschel, H., Gruenberg, E., Burke, J.D. Jr., Regier, D.A.,1984. Lifetime prevalence of specifi c psychiatric disorders in three sites. Arch Gen Psychiatry, 41, 949-958. 
Rodríguez, N., Morer, A., González-Navarro, E.A., Serra-Pages, C., Boloc, D., Torres, T., García-Cerro, S., Mas, S., Gassó, P., Lázaro, L., 2017. Inflammatory dysregulation of monocytes in pediatric patients with obsessive-compulsive disorder. J Neuroinflammation, 14(1), 261.

Rosario-Campos, M.C., Leckman, J., Mercandante, M.T., Shavitt, R.G., da Sila Prado, H., Zamignani, D., Miguel, E., 2001. Adults with early-onset obsessive compulsive disorder. Am J Psychiatry, 158, 18991903.

Rufer, M., Hand, I., Alsleben, H., Braatz, A., Ortmann, J., Katenkamp, B., Fricke, S., Peter, H. (2005). Longterm course and outcome of obsessive-compulsive patients after cognitive-behavioral therapy in combination with either fluvoxamine or placebo. European Archives of Psychiatry and Clinical Neuroscience, 255(2), 121-128.

Ruscio, A.M., Stein, D.J., Chiu, W.T., Kessler, R.C., 2010.The epidemiology of obsessive-compulsive disorder in the National Comorbidity Survey Replication. Mol Psychiatry. 15(1), 53-63. doi: 10.1038/mp.2008.94.

Schrag, A. , Martino, D., Apter, A., Ball, J., Bartolini, E., Benaroya-Milshtein, N., Buttiglione, M., Cardona, F., Creti, R., Efstratiou, A., Gariup, M., Georgitsi, M., Hedderly, T., Heyman, I., Margarit, I., Mir, P., Moll, N., Morer, A., Müller, N., Müller-Vahl, K., Münchau, A., Orefici, G., Plessen, K.J., Porcelli, C., Paschou, P., Rizzo, R., Roessner, V., Schwarz, M.J., Steinberg, T., Tagwerker Gloor, F., Tarnok, Z., Walitza, S., Dietrich, A., Hoekstra, P.J., EMTICS Collaborative Group, 2018. European Multicentre Tics in Children Studies (EMTICS): protocol for two cohort studies to assess risk factors for tic onset and exacerbation in children and adolescents. Eur Child Adolesc Psychiatry. 2018 Jul 7. doi: 10.1007/s00787-018-1190-4. [Epub ahead of print] 
Skoog, G., Skoog, I., 1999. A 40-Year Follow-up of Patients With Obsessive-compulsive Disorder. Arch Gen Psychiatry, 56(2), 121-127. doi:10.1001/archpsyc.56.2.121

Skapinakis, P., Caldwell, D., Hollingworth, W., Bryden, P., Fineberg, N., Salkovskis, P., Welton, N., Baxter, H., Kessler, D., Churchill, R., Lewis, G., 2016a. Pharmacological and psychotherapeutic interventions for management of obsessive-compulsive disorder in adults: a systematic review and network meta-analysis. Lancet Psychiatry, 3(8), 730-739.

Skapinakis, P., Caldwell, D., Hollingworth, W., Bryden, P., Fineberg, N., Salkovskis, P., Welton, N., Baxter, H., Kessler, D., Churchill, R., Lewis, G., 2016b. A systematic review of the clinical effectiveness and costeffectiveness of pharmacological and psychological interventions for the management of obsessivecompulsive disorder in children/adolescents and adults. Health Technol Assess. 20, 1-392.

Snider, L. A., Lougee, L., Slattery, M., Grant, P. \& Swedo, S. E., 2005. Antibiotic prophylaxis with azithromycin or penicillin for childhood-onset neuropsychiatric disorders. Biological Psychiatry, 57, 788792.

Spartz, E.J., Freeman, G.M. Jr, Brown, K., Farhadian, B., Thienemann, M., Frankovich, J., 2017. Course of Neuropsychiatric Symptoms After Introduction and Removal of Nonsteroidal Anti-Inflammatory Drugs: A Pediatric Observational Study. J Child Adolesc Psychopharmacol. 27(7), 652-659.

Stengler, K., Olbrich, S., Heider, D., Dietrich, S., Riedel-Heller, S., Jahn, I., 2013. Mental health treatment seeking among patients with OCD: impact of age of onset. Soc Psychiatry Psychiatr Epidemiol. 48(5), 8139.

Stewart, S.E., Rosario, M.C., Brown, T.A., Carter, A.S., Leckman, J.F., Sukhodolsky, D., Katsovitch, L., King, R., Geller, D., Pauls, D.L., 2007. Principal components analysis of obsessive-compulsive disorder symptoms in children and adolescents. Biol Psychiatry 61, 285-91. doi: 10.1016/j.biopsych.2006.08.040. 
Stewart, S.E., Geller, D.A., Jenike, M., Pauls, D., Shaw, D., Mullin, B., Faraone ,S.V., 2004. Long-term outcome of pediatric obsessive-compulsive disorder: A meta-analysis and qualitative review of the literature. Acta Psychiatr Scand. 110, 4-13. doi: 10.1111/j.1600-0447.2004.00302.x.

Storch, E.A., Muroff, J., Lewin, A.B., Geller, D., Ross, A., McCarthy, K., Morgan, J., Murphy, T.K., Frost, R., Steketee, G., 2011. Development and preliminary psychometric evaluation of the Children's Saving Inventory. Child Psychiatry Hum Dev. 42, 166-82. doi: 10.1007/s10578-010-0207-0

Storch, E.A., De Nadai ,A.S., Jacob, M.L., Lewin, A.B., Muroff, J., Eisen, J., Abramowitz, J.S., Geller, D.A., Murphy, T.K., 2014. Phenomenology and correlates of insight in pediatric obsessive-compulsive disorder. Compr Psychiatry. 55, 613-20. doi: 10.1016/j.comppsych.2013.09.014.

Storch, E.A., Small, B.J., McGuire, J.F., Murphy, T.K., Wilhelm, S., Geller, D.A., 2018. Quality of Life in Children and Youth with Obsessive Compulsive Disorder. Journal of Child and Adolescent Psychopharmacology, 28, 104-110.

Subramaniam, M., Soh, P., Vaingankar, J.A., Picco, L., Chong ,S.A., 2013. Quality of life in obsessivecompulsive disorder: impact of the disorder and of treatment. CNS Drugs, 27, 367-83.

Swedo, S.E., Leonard, H.L., Garvey, M., Mittleman, B., Allen, A.J., Perlmutter, S., Lougee, L., Dow, S., Zamkoff, J., Dubbert, B.K., 1998. Pediatric autoimmune neuropsychiatric disorders associated with streptococcal infections: clinical description of the first 50 cases. Am J Psychiatry, 155(2), 264-271.

The National Institute of Mental Health (2017). Technology and the Future of Mental Health Treatment. Retrieved from: https://www.nimh.nih.gov/health/topics/technology-and-the-future-of-mental-healthtreatment/index.shtml

Taylor, S., 2011. Early versus late onset obsessive-compulsive disorder: evidence for distinct subtypes. Clin Psychol Rev. 31(7):, 1083-100. doi: 10.1016/j.cpr.2011.06.007. PMID:21820387 
Tylee, D.S., Sun, J., Hess, J.L., Tahir, M.A., Sharma, E., Malik, R., Worrall, B.B., Levine, A.J., Martinson, J.J., Nejentsev, S., Speed, D., Fischer, A., Mick, E., Walker, B.R., Crawford, A., Grant, S.F.A., Polychronakos, C., Bradfield, J.P., Sleiman, P.M.A, Hakonarson, H., Ellinghaus, E., Elder, J.T., Tsoi, L.C., Trembath, R.C., Barker, J.N., Franke, A., Dehghan, A., 23 and Me Research Team, Inflammation Working Group of the CHARGE Consortium, METASTROKE Consortium of the International Stroke Genetics Consortium, Netherlands Twin Registry, neuroCHARGE Working Group, Obsessive Compulsive and Tourette Syndrome Working Group of the Psychiatric Genomics Consortium, Faraone, S.V., Glatt ,S.J. , 2018. Genetic correlations among psychiatric and immune-related phenotypes based on genome-wide association data. Am J Med Genet B Neuropsychiatr Genet. 177(7), 641-657. doi: 10.1002/ajmg.b.32652.

van Grootheest, D.S., Bartels, M., Cath, D.C., Beekman, A.T., Hudziak, J.J., Boomsma, D.I., 2007. Genetic and environmental contributions underlying stability in childhood obsessive-compulsive behavior. Biol Psychiatry, 61(3), 308-15.

Viswanath, B., Narayanaswamy, J.C., Cherian, A.V., Reddy, Y.C.J., Math, S.B., 2011. Is familial ObsessiveCompulsive disorder different from sporadic Obsessive-Compulsive Disorder? A comparison of clinical characteristics, comorbidity and treatment response. Psychopathology, 44(2), 83-89.

Volkmar, F., Siegel, M., Woodbury-Smith, M., King, B., McCracken, J., State, M., Child, A. A., 2014. Practice parameter for the assessment and treatment of children and adolescents with autism spectrum disorder. Journal of the American Academy of Child \& Adolescent Psychiatry, 53(2), 237-257.

Walitza, S., Marinova, Z., Grünblatt, E., Lazic, S.E., Remschmidt, H., Vloet, T.D., Wendland, J.R., 2014. Trio study and meta-analysis support the association of genetic variation at the serotonin transporter with early-onset obsessive-compulsive disorder. Neurosci Lett. 580, 100-3. doi: 10.1016/j.neulet.2014.07.038. PMID: 25093702 
Walitza, S., Wendland, J.R. , Gruenblatt, E. , Warnke, A. , Sontag, T.A. , Tucha, O., Lange, K.W ., 2010. Genetics of early-onset obsessive-compulsive disorder. Eur Child Adolesc Psychiat 19, 227- 235.

Walitza, S., Zellmann, H., Irblich, B., Lange, K.W., Tucha, O., Hemminger, U., Wucherer, K., Rost, V., Reinecker ,H., Wewetzer, C., Warnke, A., 2008. Children and adolescents with obsessive-compulsive disorder and comorbid attention-deficit/hyperactivity disorder: preliminary results of a prospective follow-up study. J Neural Transm (Vienna),115(2), 187-90. doi: 10.1007/s00702-007-0841-2.

Wang, L.Y., Chen, S.F., Chiang, J.H., Hsu C.Y., Shen, Y.C., 2018. Systemic autoimmune diseases are associated with an increased risk of obsessive-compulsive disorder: a nationwide population-based cohort study. Social Psychiatry and Psychiatric Epidemiology, published online $7^{\text {th }}$ November 2018. https://doi.org/10.1007/s00127-018-1622-y.

Weissman, M.M. , Bland, R.C. , Canino, G.J. , Greenwald, S. , Hwu, H.G. , Lee, C.K., Newman, S.C., OakleyBrowne, M.A., Rubio-Stipec, M., Wickramaratne, P.J., 1994. The cross national epidemiology of obsessive compulsive disorder. Cross National Collaborative Group . J Clin Psychiatry, 55, 5- 10.

Williams, K.E., Koran, L.M., 1997. Obsessive-compulsive disorder in pregnancy, the puerperium, and the premenstruum. J Clin Psychiatry, 58(7), 330-4

Williams, K.A., Swedo, S.E., Farmer, C.A., Grantz, H., Grant, P.J., D'Souza, P., Hommer, R., Katsovich, L., King, R.A., Leckman, J.F., 2016. Randomized, Controlled Trial of Intravenous Immunoglobulin for Pediatric Autoimmune Neuropsychiatric Disorders Associated with Streptococcal Infections. J Am Acad Child Adolesc Psychiatry, 55(10), 860-867

Wittchen, H.U., Jacob,i F., Rehm, J., Gustavsson, A., Svensson, M., Jönsson, B., Olesen, J., Allgulander, C., Alonso, J., Faravelli, C., Fratiglioni, L., Jennum, P., Lieb, R., Maercker ,A., van Os, J., Preisig, M., Salvador- 
Carulla, L., Simon, R., Steinhausen, H.C., 2011. The size and burden of mental disorders and other disorders of the brain in Europe 2010. Eur Neuropsychopharmacol. 21, 655-679.

World Health Organization Report (2011). mHealth: New horizons for health through mobile technologies. World Health Organization, 64(7), 66-71.

World Health Organization. (2018). The precautionary principle: Public health, protection of children and sustainability. Retrieved April 15, 2018, from

http://www.who.int/hia/examples/overview/whohia076/en/

Zellmann, H., Jans, T., Irblich, B., Hemminger, U., Reinecker, H., Sauer, C., Lange, K.W., Tucha, O., Wewetzer ,C., Warnke, A., Walitza, S., 2009 [Children and adolescents with obsessive-compulsive disorders]. Z Kinder Jugendpsychiatr Psychother. 37(3), 173-82. doi: 10.1024/1422-4917.37.3.173. [Article in German]

Zilhão, N.R., Abdellaoui ,A., Smit, D.J.A., Cath, D.C., Hottenga, J.J., Boomsma, D.I., 2018. Polygenic prediction of obsessive compulsive symptoms. Mol Psychiatry, 23(2), 168-169. 